المجلة الدولية للدراسات التربوية والنفسية

$$
\text { بحث رقم } 8
$$

\title{
المناعة النفسية والمساندة الاجتماعية \\ كمنبئات بالتوجه الإيجابي نحو المستقبل لدى عينة من طالبات جامعة القصيم
}

\author{
حنان خليل الحلبي \\ أستاذ الصحة النفسية المساعد بقسم علم النفس \\ كلية التربية ببريدة- جامعة القصيم- السعودية \\ dr.hanan9591@yahoo.com
}


المنـاعـة النفسية والمسـاندة الاجتماعية كمـنبئات بالتوجه الإيجابي نحو المستقبل لدى عينة من طالبات جامعة القصيم

\author{
حنان خليل الحلبي \\ أستاذ الصحة النفسية المساعد بقسم علم النفس- كلية التربية ببريدة- جامعة القصيم- السعودية \\ dr.hanan9591@yahoo.com
}

DOI: https://doi.org/10.31559/EPS2021.9.2.8 2020/8/15 مراجعة البحث: 2020/8/22 قبول البحث: 2020/30

هدفت الدراسـة إلى التعرف على دور المناعة النفسية والمساندة الاجتماعية في التنبؤ بالتوجه الإيجابي نحو المستقبل لدى طالبات

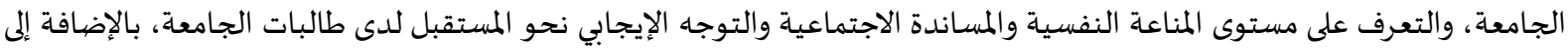
التعرف على الفروق بين مرتفعي ومنخفضي المناعة النفسية، والفروق بين مرتفعي ومنخفضي المساندة الاجتماعية على مقياس التوجاء

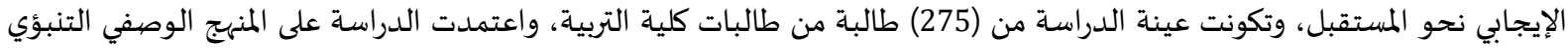
المقارن، وتم استخدام مقياس المناعة النفسية لطالبات الجامعة، ومقياس المساندة الاجتماعية للمراهقين والشباب، ومقياس التوجهاء الإيجابي نحو المستقبل، وتوصلت الدراسة إلى النتائج التالية: يتمتع أفراد العينة بمستوى أعلى من المتوسط في المناعة النفسية، ومستوى أقل من المتوسط في المساندة الاجتماعية والتوجه نحو المستقبل، وللمناعة النفسية قدرة تنبؤيها بالتوجه الإيجابي نحو المستقبل، بينما لم

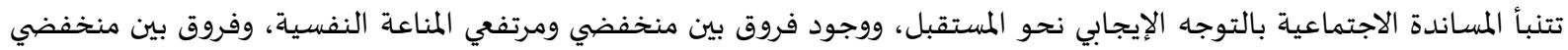

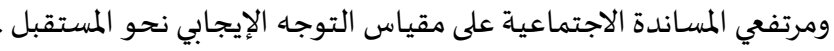
الكلمات المفتاحية: المناعاة النفسية؛ المساندة الاجتماعية؛ التوجه الإيجابي نحو المستقبل .

يعيش الانسان اليوم واقعاً صعباً، ويواجه تحديات كثيرة، ومع ضغوط الحياة والأعباء والأزمات، يصبح الفرد أكثر عرضة للاضطرابات، إلا أن الناس يختلفون في تفسيرهم للواقع وفي تعاملهم مع الأحد اث والظروف، كما يختلفون في توجهاتهم نحو المستقبل، فالبعض ونات يتمتع بالمناعاة النفسية التي تشكل درعاً واقياً يساعده على مواجهة هذه الضغوط والأزمات، وتكوين اتجاه إيجابي نحو المستقبل، بينما البعض الآخر يفتقد للقدر الكافي من المناعة

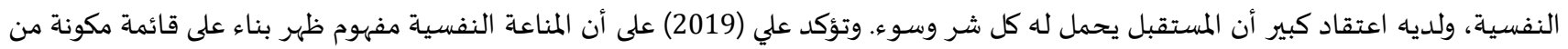

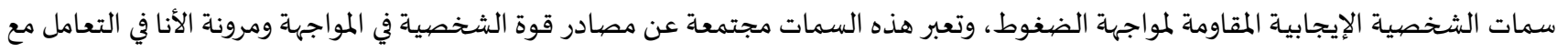
المشكلات والضغوط والتوجه نحو الهدف، حيث تعمل هذه المصادر كآليات معرفية تكمن وراء العديد من الانفعالات الإيجابية بما تقوم باه من دور

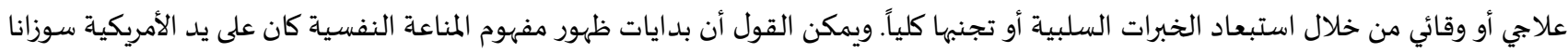
كوبازا Suzanna Kobassa أثناء إعدادها لرسالة الدكتوراه تحت إشراف أستاذها مادي Maddi بجامعة شيكاغو بالولايات المتحدة الأمريكية والتي انتهت منها في سنة 1977، وقد وصفت كوبازا (1979) Kobassa المناعة النفسية بأنها مجموعة من السمات الشخصية تعمل كواق لأحداث الحياء الحياة

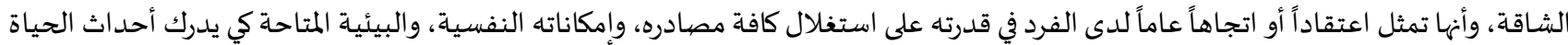

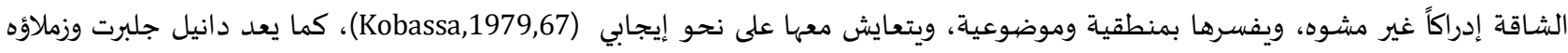
(1998) أول من أشار إلى مفهوم المناعة النفسية، في حين يعد أولاه (Olah) من أكثر الباحثين نشراً ودراسة لهذا المفهوم. 
ويرى أولاه (2002) Olah أن المناعة النفسية Psychological Immunity نظام متكامل من الأبعاد المعرفية والد افعية والسلوكية للشخصية

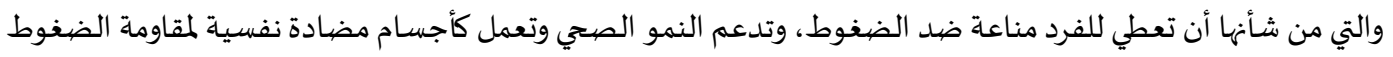

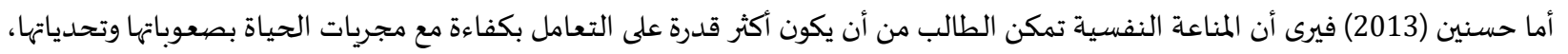
وعلى تحديد أهداف واقعية والسعي الدؤوب لتحقيقها، ويشير كل من باردواج واكروال (Bhardwaj \&Agrwal,2015) في دراستهما للمناعة النفسية إلى إلى

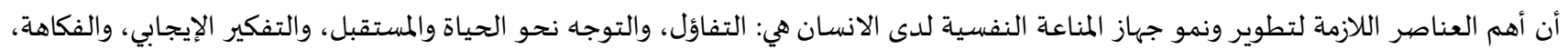
والقدرة على التكيف والمرونة .

وقد حظيت المساندة الاجتماعية Social Support باهتمام أكبر من الباحثين بعد أن نشر كابلن (Caplan, 1974) دراسته التي تضمنت أصنافاً

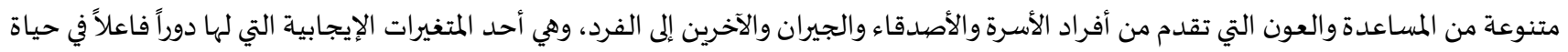

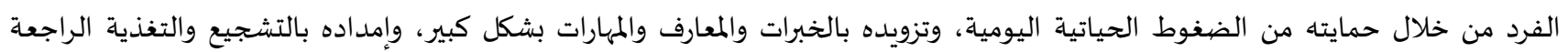

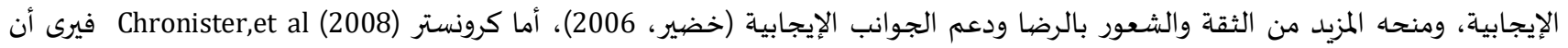

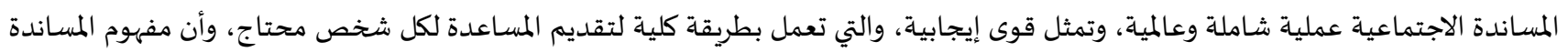

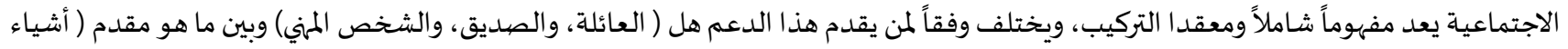

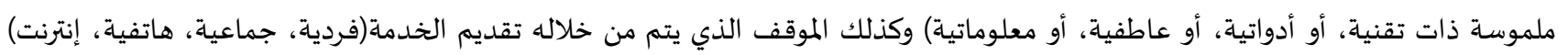

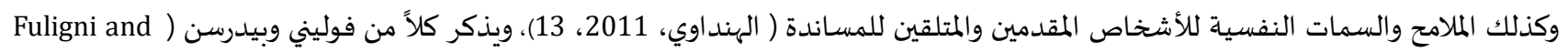

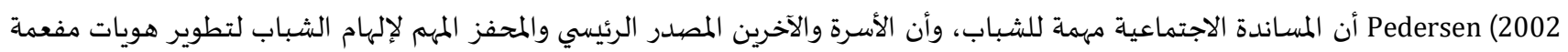

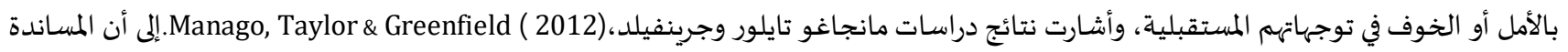

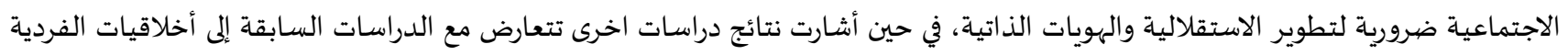

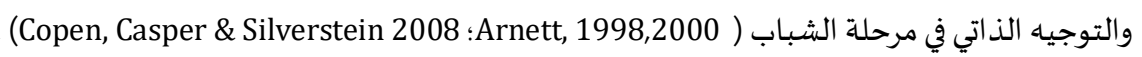
كما حظي التوجه المستقبلي Future Orientation باهتمام كبير من قبل علماء النفس، فقد أشار (فرانكل، 1982) إلى أن فقدان الثقان الثقة في

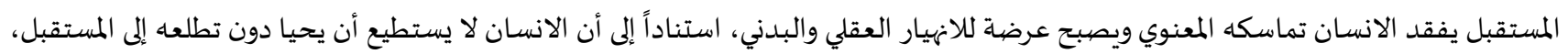

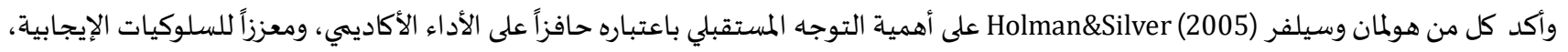

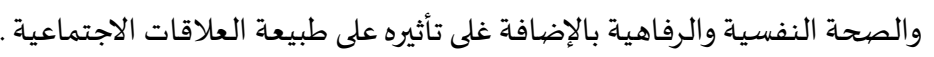

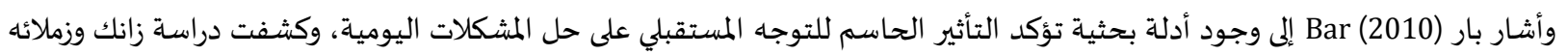
(Zhang et.al,2009)

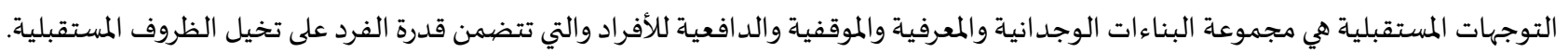

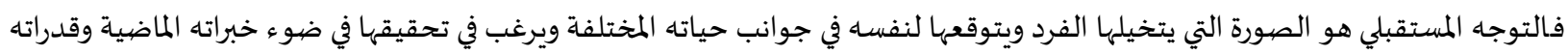

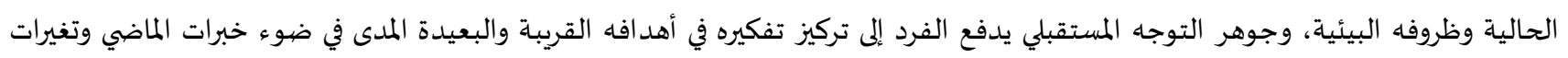

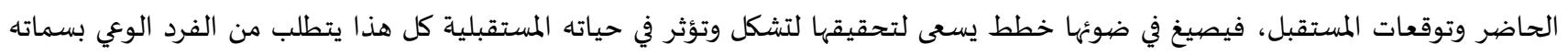

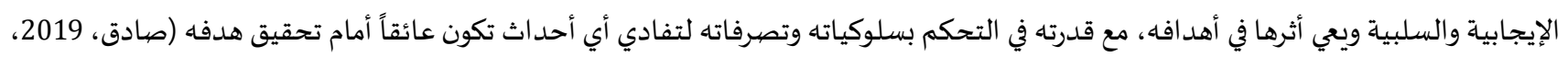

وتؤكد سيجنر (2009) Seginer على أهمية دراسة التوجه المستقبلي لدى طلاب الجامعة لأنهم أكثر الفئات العمرية تخطيطاً للمستقبل واهتماماً

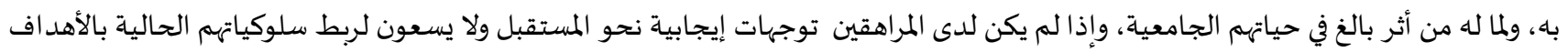

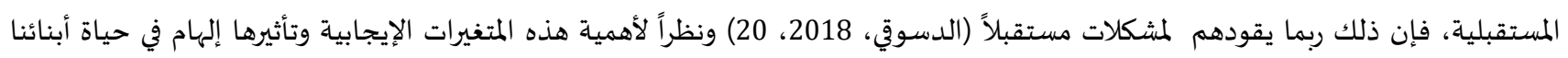

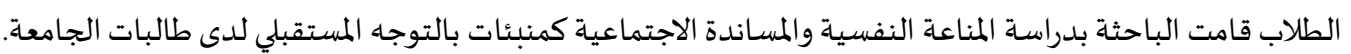

مشكلة الدراسـة:

يتعرض طلاب الجامعة في مختلف المستويات إلى الكثير من المواقف والمصاعب الحياتية التي تقلقهم وتثير التوتر والاضطرابات النفسية لديهم،

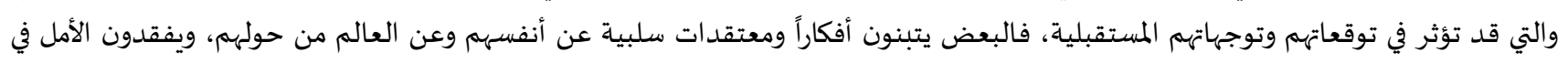

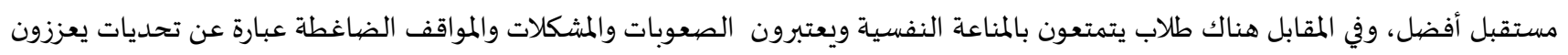
من خلالها ثقتهم بأنفسهم ويستشعرون قيمة ذواتهم وقدراتهم في حل ما يقابلهم من مشكلات، ويتبنون توجهات إيجابية نحو المستقبل، فقدل توصلت

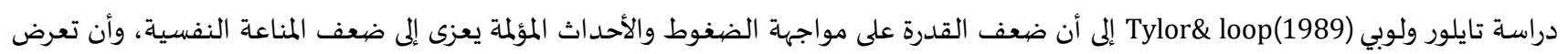
الفرد للصدمات والضغوط وإدراكه بعدم القدرة على مواجهتها أو التنبؤ بنتائجها يجعل الفرد يشعر بالتوجس والئس والعجز واليأس والتشاؤم بشأن 
المستقبل،(عبد الجبار، 2010، 2)، ومع ازدياد الضغوط والتحديات التي تواجه طالباتنا في مختلف جوانب الحياة وانعكاس آثارها على حياة الطالبة

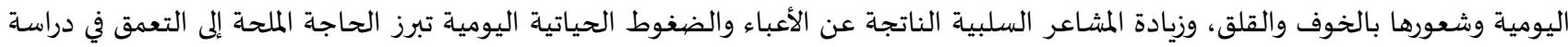

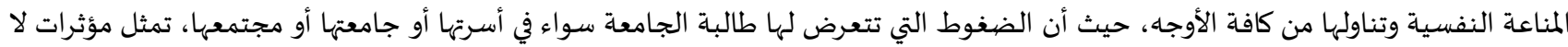

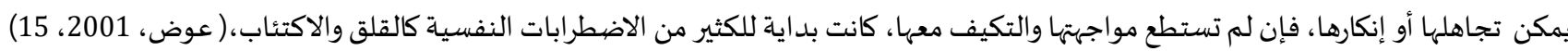

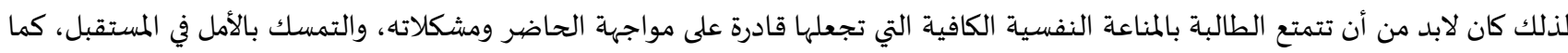
يؤكد مطلك (2007) على أهمية دور المساندة الاجتماعية من قبل الأهل وأن أهم التحديات التي تواجه الفرد في توجهه نحو المستقبل هي التحديات

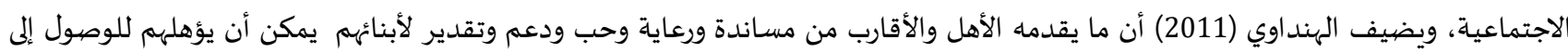

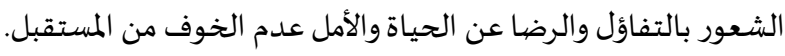

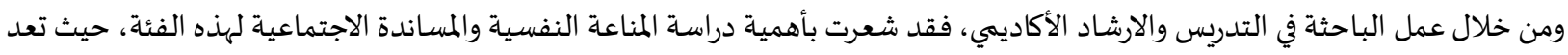

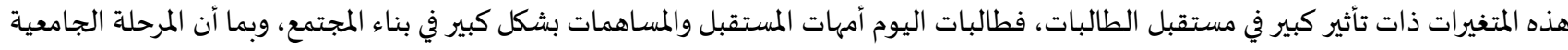

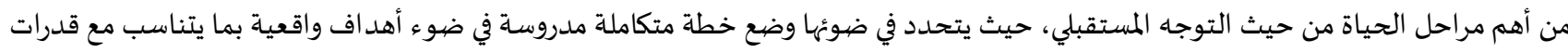

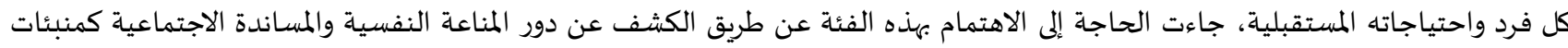

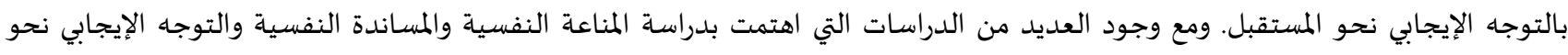

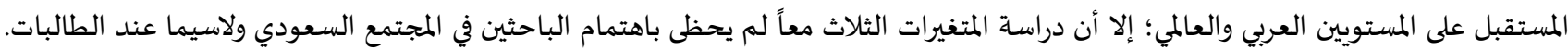
وبناء على ذلك تتحد مشكلة الدراسـة في الإجابة على التساؤلات التالية:

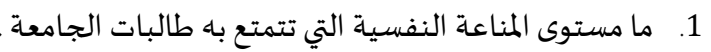
2. ما مستوى المساندة الاجتماعية التي تتمتع به طالبات الجامعاة.

3. ما مستوى التوجهات المستقبلية التي تتمتع باه طالبات الجامعة.

4. هل يمكن للمناعاة النفسية والمساندة الاجتماعية التنبؤ بالتوجه الإيجابي نحو المستقبل لدى طالبات الجامعة. 5. هل توجد فروق بين مرتفعي المناعة النفسية ومنخفضي المناعة النفسية على مقياس التوجاه الإيجابي نحو المستقبل . 6. هل توجد فروق بين مرتفعي المساندة الاجتماعية ومنخفضي المساندة الاجتماعية على مقياس التوجه الإيجابي نحو المستقبل .

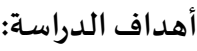

تهدف الدراسـة الحالية إلى:

1. تعرف مستوى المناعة النفسية لدى طالبات الجامعة. 2. ت تعرف مستوى المساندة الاجتماعية لدى طالبات الجامعة.

3. تعرف مستوى التوجه الإيجابي نحو المستقبل لدى طالبات الجامعة.

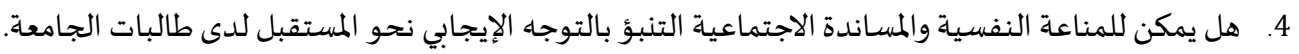
5. التعرف على الفروق بين مرتفعي المناعة النفسية ومنخفضي المناعة النفسية على مقياس التوجاء الإيجابي نحو المستقبل. 6. التعرف على الفروق بين مرتفعي المساندة الاجتماعية ومنخفضي المساندة الاجتماعية على مقياس التوجه نحو المستقبل .

أهمية الدراسـة:

الأهمية النظرية:

تسليط الضيوء على متغيرات هامة في علم النفس الإيجابي وهي: (المناعة النفسية، المساندة الاجتماعية، التوجه الإيجابي نحو المستقبل) والتي تغني الجانب النظري في مجال الصحة النفسية، ولما لها من دور مهم في حياة الطالبة الجامعية والاجتماعية. أهمية البعد المستقبلي في تشكيل هوية الطالب الجامعي ويتضح ذلك في متغير التوجه نحو المستقبل .

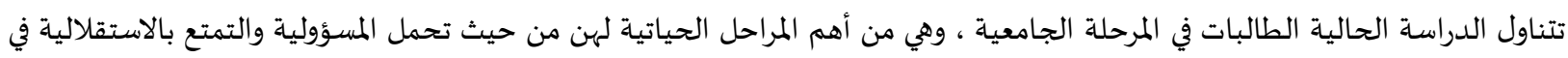
اتخاذ القرارات الحياتية في المستقبل .

الأهمية التطبيقية:

إعداد مقياس يتمتع بخصائص سيكومترية ملائمة لقياس المناعة النفسية لطالبات المرحلة الجامعية . يمكن أن تسهم الدراسة الحالية في وضع برامج إرشادية وعلاجية تقوم على تنمية المناعة النفسية والتوجه الإيجابي نحو المستقبل . 
تزويد الطالبات -والمرشدات - بدراسة حديثة وخاصة أن هناك ندرة في الدراسات التي تناولت المتغيرات الثلاث معاً: المناعة النفسية والمساندة الاجتماعية والاتجاه الإيجابي نحو المستقبل .

$$
\text { الحدود الدراسـة: الحدود البشرية: طالبات كلية التربية ببريدة / قسم علم النفس المكانية: كلية التربية ببريدة . }
$$

مصطلحات الدراسة:

المناعة النفسية Psychological Immunity : ويعرفها الأحمد (2020) بأهها نظام وجداني يستعين به الفرد بهدف إعطاء القدرة على إدراك المخاطر النفسية والحماية منها وتعزنز الحياة0( الأحمد، 2020 ، 129).

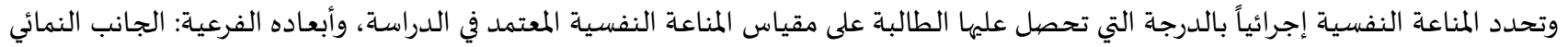

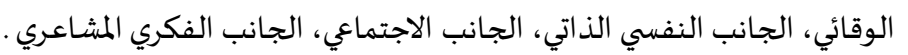
المساندة الاجتماعية Social Support: سوف تتبنى الدراسة الحالية تعريف السرسي وعبد المقصود (2016) للمساندة الاجتماعية بأها " الدعم

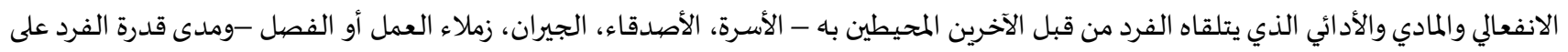

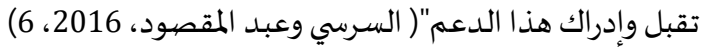
وتحدد المساندة الاجتماعية إجرائياً بالدرجة التي تحصل وعلد عليها الطالبة على مقديلى مقياس المساندة الاجتماعية المعتمد في الدراسة، وأبعاده الفرعية: المساندة

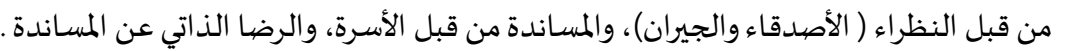
التوجه الإيجابي نحو المستقبل Positive Orientation Towards the Future : سوف تتبنى الدراسة الحالية تعريف أبو بكر وعبد الرسول للتوجهاء

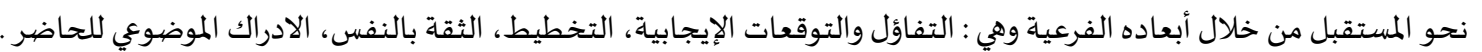
التفاؤل والتوقعات الإيجابية: أحد سمات الشخصية التي تجعل الفرد ينظر إلى المستقبل بأمل، ويتوقع أفضل النتائج؛ مما يجعله يسعى إلى تحقيق المقائ

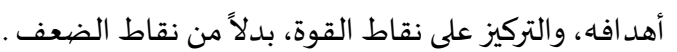
التخطيط: وضع الخطط من خلال السعي للوصول إلى نقطة محددة الملامح، وتحديد الهدف للوصول إلى النجاح، الذي يطمح الانسان إلى تحقيقه

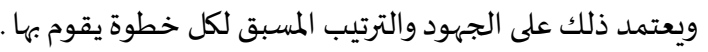
الثقة بالنفس: اتصاف الفرد بالكفاءة والقدرة على مواجهة الصعاب والظروف المختلفة، مما يتيح لله امكانيات وقدرات لتحقيق أهدافه المرجوة

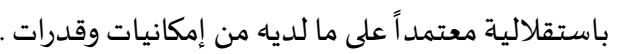

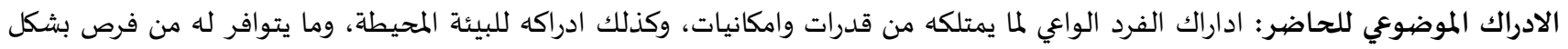
موضوعي .( أبو بكر، وعبد الرسول، 2020، 7 )

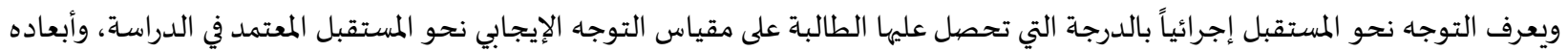

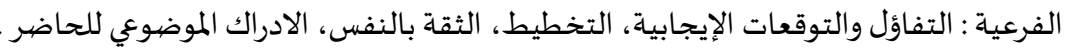

\section{الإطار النظري والدراسات السابقة:}

المناعة النفسية Psychological Immunity لقد تزايد الاهتمام في الآونة الاخيرة في علم النفس الإيجابي وموضوعاته، وتعد المناعة النفسية من

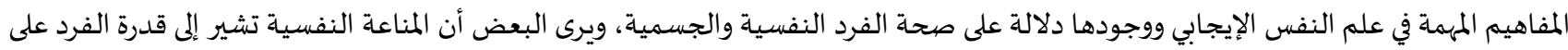

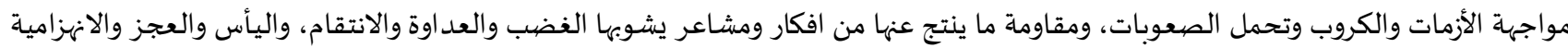

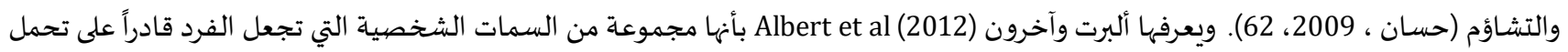
التأثيرات الناتجة عن الضغوط والانهاك النفسي، ودمج كافة الخبرات المكتسبة لاستخدامها في المواقف المشابهة (Albert et al, 2012. p104 ) ، ويؤكد Bredacs (2016) الأهد اف، وبهذه الطريقة فهي أحد العوامل المهيمنة على تحفيز الطلاب أيضًا. وتنوعت النظريات التي تناولت المناعة النفسية، حيث تعاملت نظرية التحليل النفسي مع المناعة النفسية على أنها قوة الأنا وقدرتها على إحداث

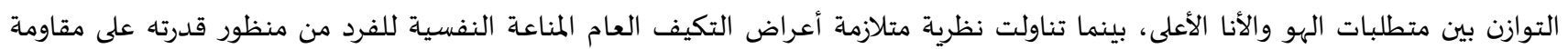


الضغوط، في حين أن النظرية المعرفية تناولت المناعة النفسية من منطلق رؤية الفرد للموقف بشمولية وقدرته على أن يسلك سلوكاً إيجابياً وفقاً لهذه الرؤية ( الجزار، 2018، 7و ) وتعرف الباحثة المناعة النفسية من خلال أبعادها الفرعية وهي: الجانب النمائي الوقائي، الجانب النفسي الذاتي، الجانب الاجتماعي، الجانب الفكري المشاعري .

البعد الأول الجانب النمائي الوقائي: ويقيس امتلاك الطالبة للجوانب الإيجابية في حياتها، حيث يركز النمائي على جوانب القوة عند الطالبة أما الوقائي فيركز على التحصين النفسي . البعد الثاني الجانب النفسي الذاتي: ويقيس الجانب النفسي والذاتي للطالبة وآلية تنظيمها لذاتها وحياتها الشخصية والجامعياة، وسعادهها وتفاؤلها وتمتعها باستقرار نفسي يساعدها في الوصول إلى المناعة النفسية . البعد الثالث الجانب الاجتماعي: وهو البعد الذي يهتم بالعلاقات مع الآخرين، وإيجابية الطالبة في علاقاتها مع الآخرين مما يحافظ على مناعتها النفسية. البعد الر ابع الجانب الفكري المشـاعري: ويقيس تمتع الطالبة بجانب إيجابي من الأفكار المناسبة، والمشاعر الإيجابية التي تعمل كسد منيع في

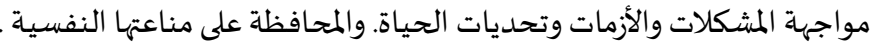
ويمكن القول أن المناعة النفسية تعد بمثابة القوة التي تساعد الفرد على مواجهة التحديات والمشككلات، والتغلب واتبات على الازمات وتجاوز العثرات لتحقيق النجاحات والتطلع إلى ستقبل أفضل المسـاندة الاجتماعية Social Support: تعتبر المسـاندة الاجتماعية من المفاهيم التي اختلف الباحثون في طريقة تناولها تبعاً لتوجهاتهم النظرية، فقد تناول علماء الاجتماع هذا المفهوم في إطار تناولهم للعلاقات الاجتماعية، ويعد مصطيح شبكاعة العلاقات الاجتماعية الماعية البداية الحقيقية لظهور مصطلح المساندة الاجتماعية، ويطلق عليه البعض مصطلح الموارد أو الإمكانات الاجتماعية بينما يحدده البعض على أنه إمدادات اجتماعية

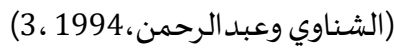

وبصفة عامة مهما كان الاساس النظري الذي ينطلق منه اصطلاح المساندة الاجتماعية، فإنها يشتمل علي مكونين رئيسين:

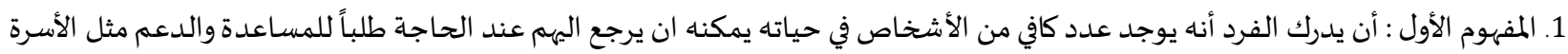

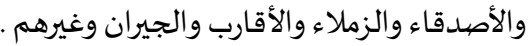

2. المفهوم الثاني : أن يكون لدي الفرد درجة من الرضا عن المساندة المتاحة والاعتقاد في كفاية المساندة. (حكيمة ، أحمد ورشيد، 2011، 9) أنماط المساندة الاجتماعية :

ويشير ( House,1981: 158) إلى أن المسـاندة الاجتماعياة يمكن أن تأخذ عدة أشكال ومنها:

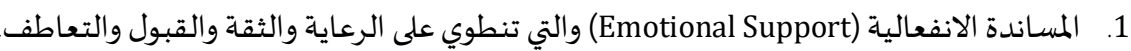
2. 3. المساندة بالمعلومات (Information Support) التي تنطوي على إعطاء نصائح أو معلومات أو تعليم مهارة تؤدي إلى حل مشكلة أو موقف فلمانف

4. مساندة الأصدقاء (Companionship Support) والتي تنطوي على ما يمكن أن يقدمه الأصدقاء لبعضهم البعض وقت الشدة. وللمساندة الاجتماعية وظائف متعددة فهي تسهم في توفير الراحة النفسية، حيث أن التفاعل الاجتماعي يولد درجة من المشاعر الإيجابية التي تحقق الصحة النفسية وتخفف المعاناة من بعض الاضطرابات النفسية كالقلق، والاكتئاب، والوحدة النفسية، كما أن لها وظيفة نمائية عندما يكون لدى الفرد شبكة من العلاقات الاجتماعية الحميمة التي تساعده على تحقيق التوافق الإيجابي، وكذلك وظيفة وقائية تتمثل في مساعدة الفرد على لمعاهي مواجهة الأحداث الخارجية التي يدركها على أهها شاقة وتمثل ضغنوط الهات عليه. مما سبق يمكن القول بأن المساندة الاجتماعية هي مقدار الدعم المعنوي

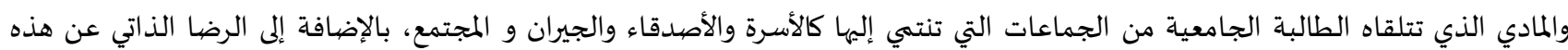

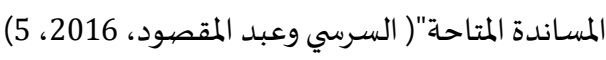
التوجه الإيجابي نحو المستقبل Positive Orientation Towards the Future : لقد حظي البعد المستقبلي وأثره في حياة الانسان باهتمام كبير في كل من التراثين الفلسفي والسيكولوجي، وقد كانت الفلسفة الوجودية هي أكثر المذاهب الفلسفية تناولاً للمستقبل كبعد زمني مميز للكائن

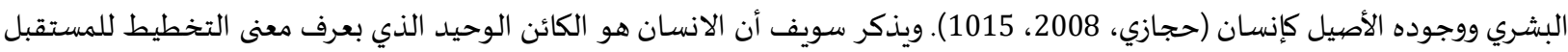

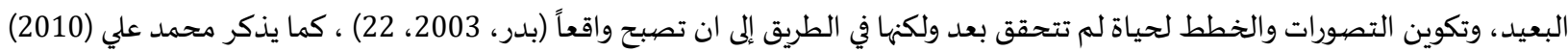
أن التوجاء نحو المستقبل هو وجهاة نظر الفرد المتضمنة مكونات معرفية وعاطفية وسلوكية حول ما سيحدث في المستقبل وتشمل وتشل العمل

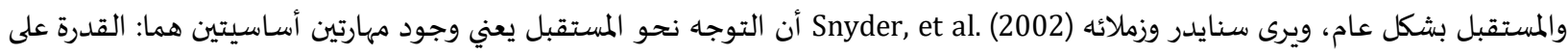


تحديد الاهداف، ورصد التقدم والأمل والتفاؤل نحو تحقيق هذه الأهداف، ووضعت سيجنر Seginer، نموذج شامل للتوجه نحو المستقبل

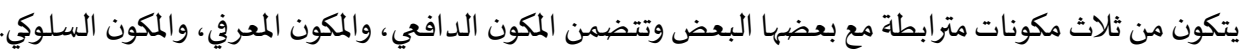

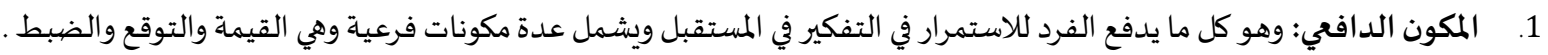
2. المكون المعرفي: ويعرف بالتمثيل المعرفي وتم وصففه من حيث بعدين وهما المحتوى والتكافؤ.

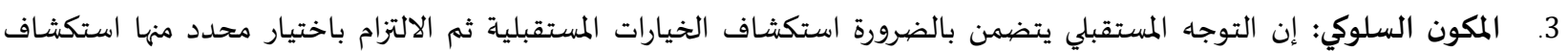

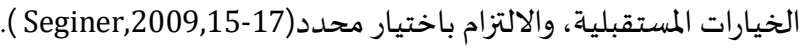

الدراسات السـابقة: وبعد اطلاع الباحثة على الدراسات السابقة والتي تناول أصحابها كلاً من المناعة النفسية والمساندة الاجتماعية والتوجاه نحو المستقبل، فقد قامت الباحثة بتقسيمها إلى ثلاثة محاور :

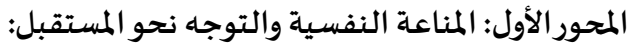
• أجرت سيفتون وسيغرستورم Sephton an Segerstrom (2010) دراسة هدفت إلى التعرف على تأثير التوقعات المتفائلة على العديد من

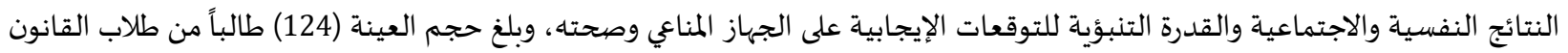

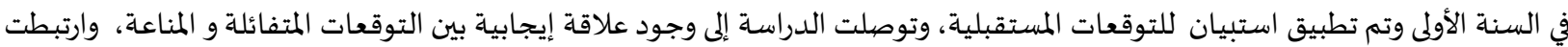
التغيرات في التفاؤل بالتغيرات في المناعة. وبينت دراسـة آدماير(2011) Admire العلاقة بين توجهات الطلاب واستجابة الجهاز المناعي لديهم، على عينة مكونة من (124) طالب من طلاب

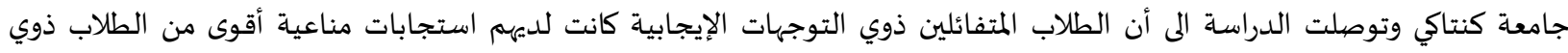
التوجهات السلبية . وكشفت دراسة بريداكس(2016) Bredacs عن الدور الذي تلعبه المناعة النفسية وعواملها الفرعية وقيمها في حياة الطلاب المشاركين في

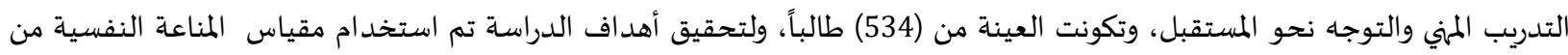
إعداد Olah وتوصلت نتائج الدراسة إلى أنه لا يوجد فرق كبير بين الجماعات في القيمة الرئيسية للمناعة النفسية، وأن الكثير من الطلاب ليس

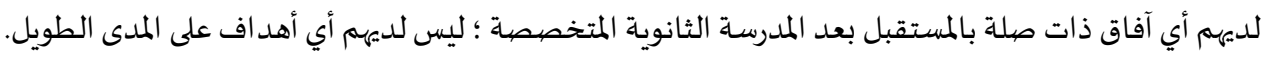

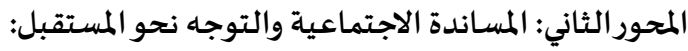
حيث أجرى سيججنر (2003) Seginer دراسـة هدفت الى التعرف على التوجاه المستقبلي للمراهقين ( المنظور الثقافي والبيئي) ودراسـة تأثير مساندة الآباء على بناء التوجاء المستقبلي للأبناء (التعليم والمهنة والزواج والأسرة) وبتحليل البيانات تبين أن مساندة الآباء تؤثر على بناء التوجاء المستقبلي للأبناء بطرق متعددة، و لأسلوب الأبوة والأمومة ومعتقدات الوالدين ذات صلة خاصة في دفع الجوانب التحفيزية للتوجه المستقبلي. وتمحورت دراسة ماريندا (2010(Marinda حول المساندة الاجتماعية من (قبل الوالدين، المعلم) والتوجه المستقبلي، والمشاركة المدرسية لدى المي طلاب المدارس الثانوية، وبلغ حجم العينة (364) مراهقاً، وأوضحت النتائج أن المشاركة المدرسية كانت مرتبطة بارة بالمسانداندة الاجتماعية من قبل

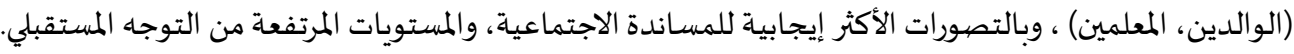

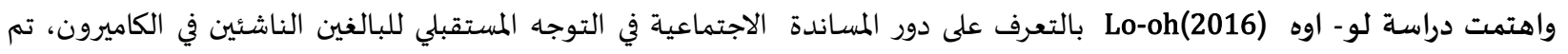
استخدام استبيان الآمال والمخاوف (Seigner, 2009) لجمع البيانات حول التوجهات المستقبلية للبالغين. وبلغت عينة الدراسة (137) طالباً من

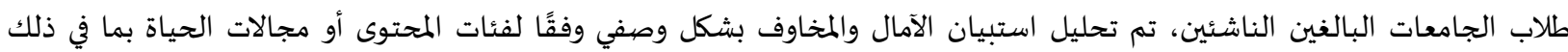

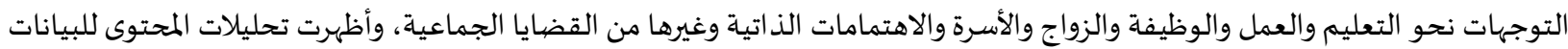

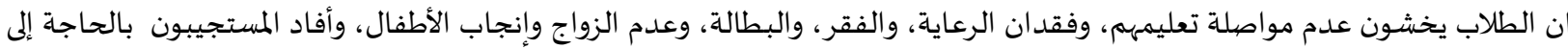

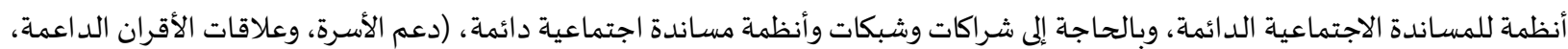

وبرامج دعم المجتمع مثل المنح الدراسية للتعليم المستمر، وفرص التدريب المهني والتوظيف والوكالات الوطنية لتنمية الشباب المنتج).

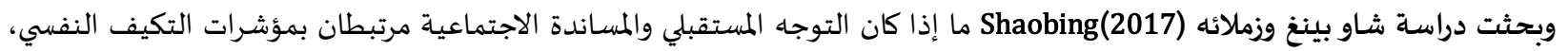
وتمت دراسة الاختلافات في التكيف النفسي بين الأطفال الذين تركواوالأطفال الذين لم يتركوا في المناطق الريفية، وتم استكشاف الأدوار الوقائية للتوجه المستقبلي والدعم الاجتماعي بالتكيف النفسي لكلا من مجموعات الأطفال، على التوالي. (دراسة طولية) شملت العينة 897 طفلاً في

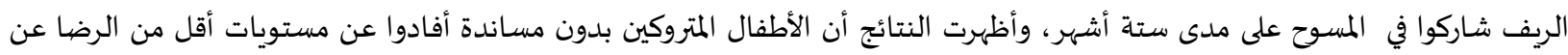
الحياة، والرضا عن المدرسة، والسعادة، بالإضافة إلى مستوى أعلى من الوحدة، والأطفال الذين حصلوا على درجات عالية في التوجه المستقبلي ، 
وخاصة التوقعات المستقبلية ، كانت درجاتهم أعلى في معظم مؤشرات التكيف النفسي المقاسة في نفس الوقت، وتنبأ كل من المساندة الاجتماعية

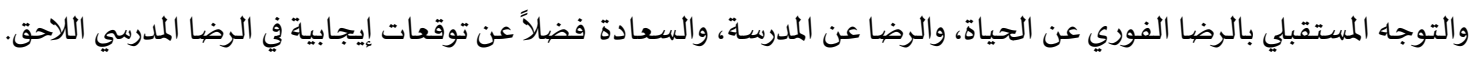

المحور الثالث: المناعة النفسية والمساندة الاجتماعية:

• وضحت دراسة بارون وزملائه (1990) مالعلاقة بين المساندة الاجتماعية والوظيفة المناعية بين أزواج مرضى السرطان، وأظهرت

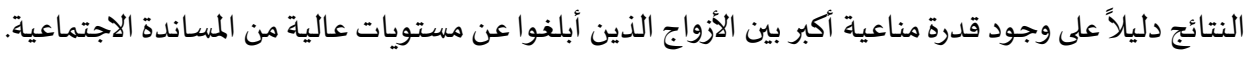

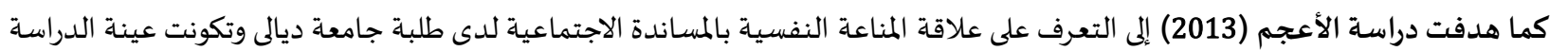

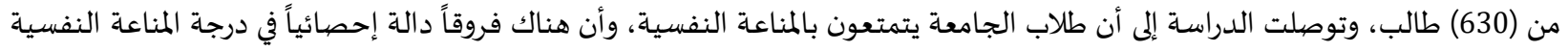

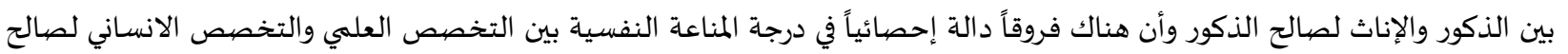

وكثفت دراسة مالود (2018) عن العلاقة المناعة النفسية والمساندة الاجتماعية، وتكونت عينة الدراسة من (120) طالباً وطالبة من كلية

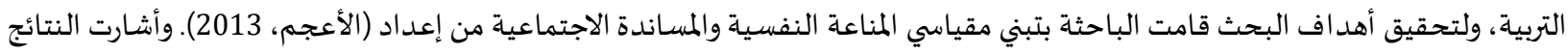

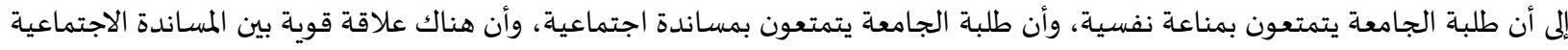
والمناعة النفسية. كما سعت دراسة النة Anubhuti (2018) إلى فحص مساهمة الموارد الشخصية (تقاس بالمناعة النفسية التي تحتوي على ثلاثة

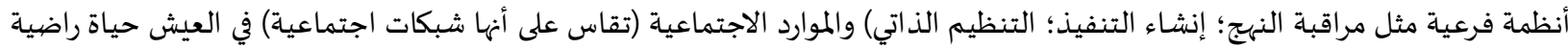

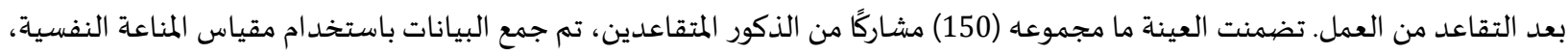

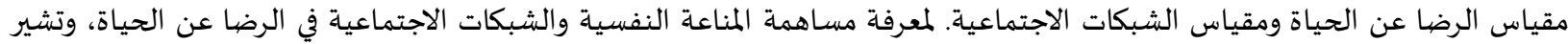

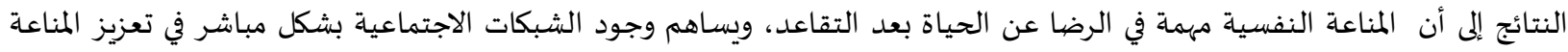
النفسية ثم يؤدي إلى الرضا المستقبلي عن الحياة.

من خلال عرض الدراسات السابقة نلاحظ كايلي: • لم تعثر الباحثة على دراسة شبيهة بالدراسة الحالية من حيث دراستها للمناعة النفسية والمساندة الاجتماعية كمنبئات بالتوجه الإيجابي نحو المستقبل، وذلك في حدود علم الباحثة. هناك ندرة في الدراسات التي تناولت المتغيرات العلاقة بين المناعة النفسية والتوجه نحو المستقبل، والمساندة الاجتماعية والتوجه نحو

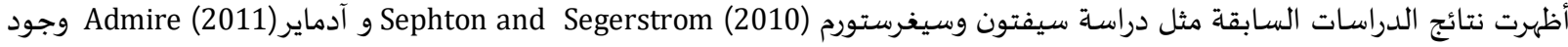

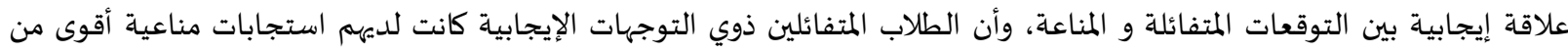

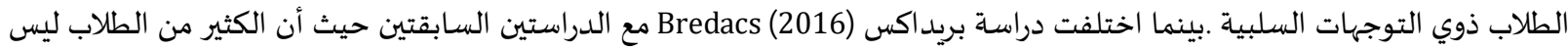

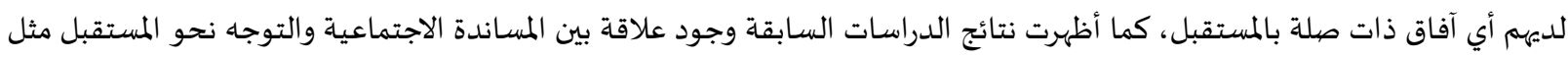

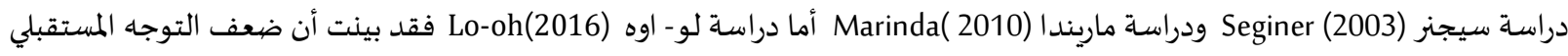

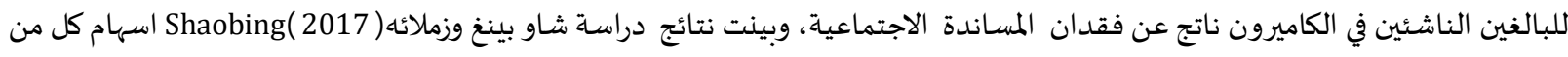

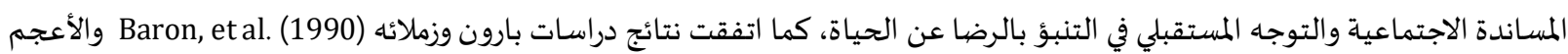
(2013) ومالود (2018) و(2018) Anubhuti على وجود علاقة موجبة بين المساندة والمناعة.

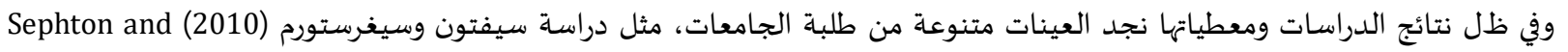

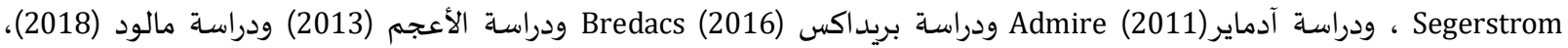

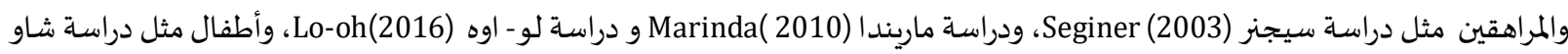

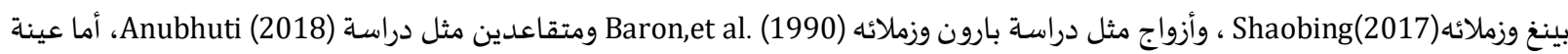
الدراسة الحالية ستكون من الطالبات الجامعيات في المجتمع السعودي. وقد استفادت الدراسة الحالياتية من نتائج الدراسات السابقة في تحديد متغيرات الدراسة والعينة وأدوات الدراسة. 
إجراءات الدراسة:

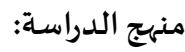

استخدمت الباحثة المنهج الوصفي التنبؤي المقارن.

المجتمع الأصلي: طالبات قسم علم النفس البالغ عددهن (501) طالبة.

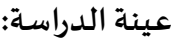

اقتصرت الدراسـة الحالية على عينة قواهها (275) طالبةً تم اختيارها بطريقة عشوائية من طالبات كلية التربية- قسم علم النفس- جامعة

القصييم للعام الجامعي 1440-1441.

أدوات الدراسـة:

أولاً: مقياس المناعة النفسية لطالبات الجامعة (إعداد الباحثة): صممت هذه الأداة بهدف قياس المناعة النفسية لدى طالبات كلية التربية، وذلك بعد الاطلاع على العديد من الدراسات مثل مقياس قصيي التخاينة وعبد الناصر القرالة (2018)، ومقياس خالد المالمالكي (2019 )، وقائمة جهاز المناعة

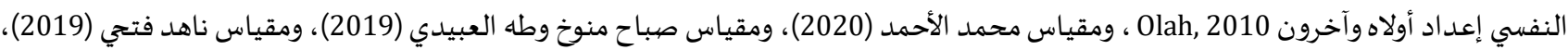

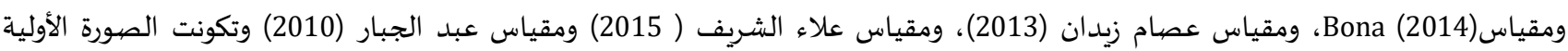
للمقياس من (40) مفردة موزعة على أربعة أبعاد كما يلي: (10) مفردات تقيس الجانب النمائي الوقائي، (10) مفردات تقيس الجانب النفسي الذاتي،

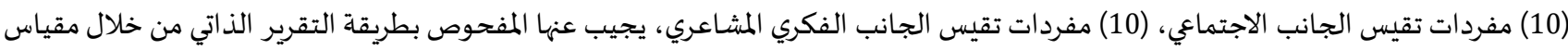

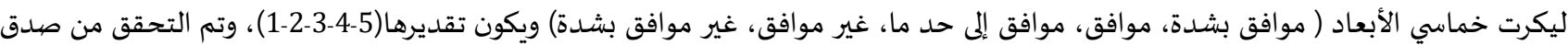

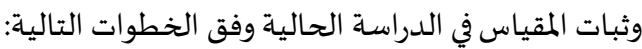

الخصائص السيكومترية للمقياس: هـدق المحكمين: تم عرض المقياس على ستة من الأساتذة المتخصصين في مجال علم النفس وذلك للتحقق من وضوح صياغة العبارات وقياسها

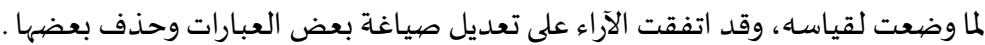
الاتساق الداخلي لمقياس المناعة النفسية لطالبات الجامعة: تم التحقق من الاتساق الداخلي للمقياس حيث تم حساب معاملات الارتباط بين درجة كل مفردة والدرجة الكلية للبعد الذي تنتمي إليه والجدول (1) يوضح قيم معاملات الارتباط، وحساب ارتباط الأبعاد مع بعضها وارتباط الأبعاد مع الدرجة الكلية لمقياس المناعة النفسية والجدول (2) يوضح قيم معاملات الارتباط

\begin{tabular}{|c|c|c|c|c|c|c|c|}
\hline الارتباط بالبعد & العبارة & الارتباط بالبعد & العبارة & الارتباط بالبعد & العبارة & الارتباط بالبعد & العبارة \\
\hline $.618^{* *}$ & 31 & $.537^{* *}$ & 21 & $.730^{* *}$ & 11 & $.724^{* *}$ & 1 \\
\hline $.587 * *$ & 32 & $.452^{* *}$ & 22 & $.741^{* *}$ & 12 & $.618^{* *}$ & 2 \\
\hline $.711^{* *}$ & 33 & $.746 * *$ & 23 & $.670^{* *}$ & 13 & $.602 * *$ & 3 \\
\hline $.709 * *$ & 34 & $.683 * *$ & 24 & $.763^{* *}$ & 14 & $.609^{* *}$ & 4 \\
\hline $.710^{* *}$ & 35 & $.729 * *$ & 25 & $.635^{* *}$ & 15 & $.701^{* *}$ & 5 \\
\hline $.800^{* *}$ & 36 & $.767^{* *}$ & 26 & $.730^{* *}$ & 16 & $.702 *$ & 6 \\
\hline $.699^{* *}$ & 37 & $.572 * *$ & 27 & $.707^{* *}$ & 17 & $.521^{* *}$ & 7 \\
\hline $.638^{* *}$ & 38 & $.766^{* *}$ & 28 & $.746^{* *}$ & 18 & $.664^{* *}$ & 8 \\
\hline $.775^{* *}$ & 39 & $.542 * *$ & 29 & $.598^{* *}$ & 19 & $.657^{* *}$ & 9 \\
\hline $.575 * *$ & 40 & $.749 * *$ & 30 & $.782 * *$ & 20 & $.609^{* *}$ & 10 \\
\hline
\end{tabular}

**. Correlation is significant at the 0.01 level (2-tailed).

ويتضح من الجدول (1) أن جميع قيم معاملات الارتباط بين العبارات والبعد الذي تنتمي إليه كانت قيماً موجبة ودالة إحصائياً وتراوحت بين

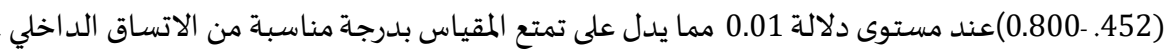

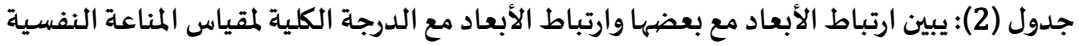

\begin{tabular}{|c|c|c|c|c|}
\hline الدرجة الكلية & المشانب الفكري & الجانب الاجتماعي & الجانب النفسي الذاتي & \\
\hline $.909^{* *}$ & $.730^{* *}$ & $.758^{* *}$ & $.855^{* *}$ & الجانب النمائي الوقائي \\
\hline $.947^{* *}$ & $.813^{* *}$ & $.776^{* *}$ & & الجانب النفسي الذاتي " \\
\hline $.887^{* *}$ & $.711^{* *}$ & & & الجانب الاجتماعي \\
\hline $.901^{* *}$ & & & & الجانب الفكري المشاعري \\
\hline
\end{tabular}

**. Correlation is significant at the 0.01 level (2-tailed). 
يتضح من الجدول (2) أن جميع قيم معاملات الارتباط بين الأبعاد مع بعضها وترابط الأبعاد مع الدرجة الكلية للمقياس كانت قيماً موجبة ودالة

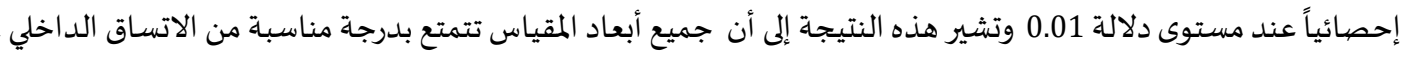

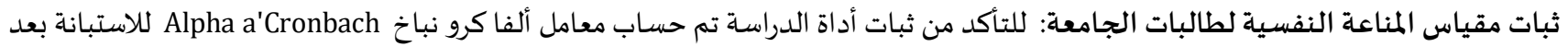
تطبيقها على العينة الاستطلاعية، كما يتضح من الجدول التبهابه

\begin{tabular}{|c|c|c|c|}
\hline الانحراف المعياري & المتوسط & معامل ثبات ألفا & مقياس المناعة النفسية \\
\hline 22.21263 & 158.3673 & .957 & \\
\hline
\end{tabular}

يتضح من الجدول السابق أن قيمة ألفا مرتفعة ودالة احصائياً، مما يدل على تمتع المقياس بدرجة مناسبة من الثبات .

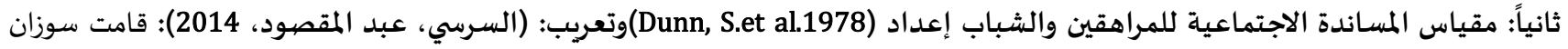
ديون وآخرون بإعداد هذه الأداة ويتكون المقياس من (25) عبارة، بهدف تقدير المساعاندة الاجتتماعية كما يدركها المراهقين والشباب، موزعة كما يلي (9)

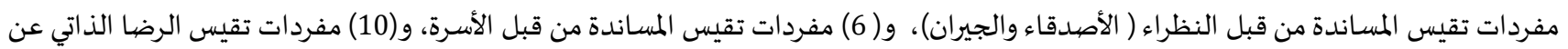

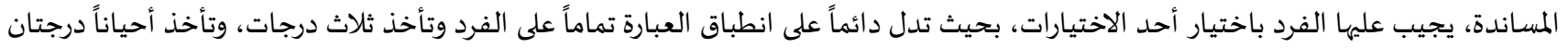

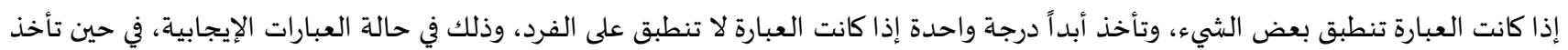

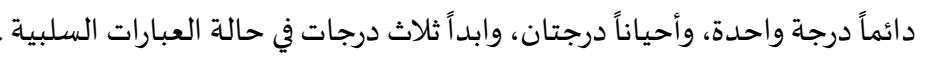
الخصيائص السيكومترية للمقياس: قامت الباحثتان (السرسي، عبد المقصود، 2014) بتعريب المقياس إلى اللغة العربية وعرضها على متخصصين باللغة العربية وعلم النفس،

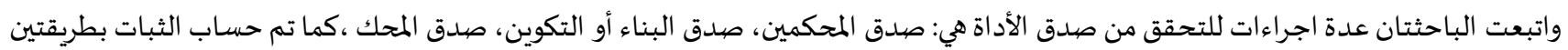

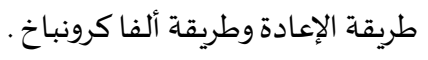

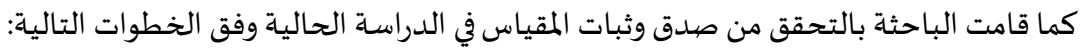
أ- صددق المحكمين: قامت الباحثة بعرض المقياس بصهورته الأولية على عدد من المحكمين بلغ عددهم ستة ( من أساتذة كلية التربية قسم علم النفس

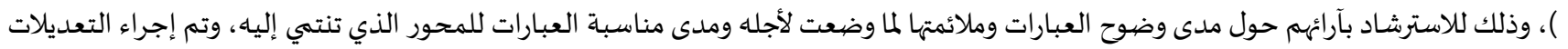
في ضوء آراء المحكمين. ب-الاتساق الداخلي لمقياس المساندة الاجتماعية للمراهقين والشباب: تم التحقق من الاتساق الداخلي للمقياس حيث تم حساب معاملات الارتباط

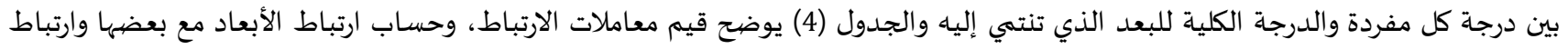
الأبعاد مع الدرجة الكلية لمقياس المساندة الاجتماعية و الجدول (5) يوضح قيم معاملات الارتباط.

\begin{tabular}{|c|c|c|c|c|c|c|c|}
\hline الارتباط بالبعد & العبارة & الارتباط بالبعد & العبارة & الارتباط بالبعد & العبارة & الارتباط بالبعد & العبارة \\
\hline $.501^{* *}$ & 22 & $.586^{* *}$ & 15 & $.728^{* *}$ & 8 & $.661^{* *}$ & 1 \\
\hline $.257^{* *}$ & 23 & $.682^{* *}$ & 16 & $.480^{* *}$ & 9 & $.698^{* *}$ & 2 \\
\hline $.319^{* *}$ & 24 & $.677^{* *}$ & 17 & $.608^{* *}$ & 10 & $.503^{* *}$ & 3 \\
\hline \multirow[t]{4}{*}{$.289^{* *}$} & 25 & $.440^{* *}$ & 18 & $.674^{* *}$ & 11 & $.677^{* *}$ & 4 \\
\hline & & $.436^{* *}$ & 19 & $.591^{* *}$ & 12 & $.785^{* *}$ & 5 \\
\hline & & $.373^{* *}$ & 20 & $.699^{* *}$ & 13 & $.580^{* *}$ & 6 \\
\hline & & $.451^{* *}$ & 21 & $.569^{* *}$ & 14 & $.660^{* *}$ & 7 \\
\hline
\end{tabular}

**. Correlation is significant at the 0.01 level (2-tailed).

ويتضح من الجدول (4) أن جميع قيم معاملات الارتباط بين العبارات والبعد الذي تنتمي إليه كانت قيماً موجبة ودالة إحصائياً، وتراوحت

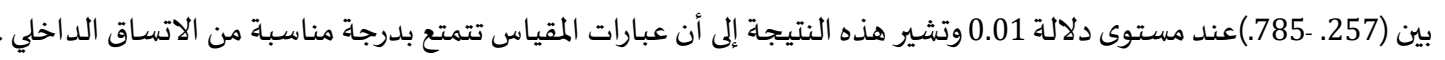
جدول (5): يبين ارتباط الأبعاد مع بعضها وارتباط الأبعاد مع الدرجة الكلية لمقياس المساندة الاجتماعية

\begin{tabular}{|c|c|c|c|}
\hline الدرجة الكلية & الرضا الذاتي عن المسـاندة & المساندة من قبل الأسرة & \\
\hline $.876^{* *}$ & $.636^{* *}$ & $.621^{* *}$ & (المساندة من قبل النظراء \\
\hline $.864^{* *}$ & $.683^{* *}$ & & المساندة من قبل الأسرة \\
\hline $.872^{* *}$ & & & الرضا الذاتي عن المساندة \\
\hline
\end{tabular}

يتضح من الجدول (5) أن جميع قيم معاملات الارتباط بين الأبعاد مع بعضها وارتباط الأبعاد مع الدرجة الكلية للمقياس كانت قيماً موجبة ودالة

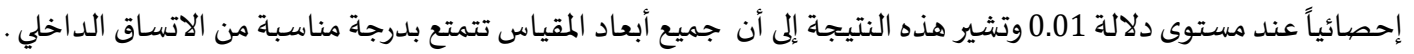


ثبات مقياس المساندة النفسية للمراهقين والشباب : للتأكد من ثبات أداة الدراسة تم حساب معامل ألفا كرو نباخ Alpha a'Cronbach للاستبانة

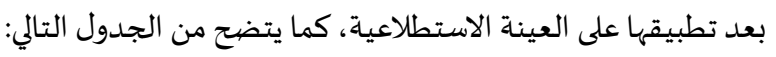

\begin{tabular}{|c|c|c|c|}
\hline الانحراف المعياري & المتوسط & معامل ثبات ألفا & مقياس المساندة النفسية \\
\hline 8.91708 & 58.7855 & .843 & \\
\hline
\end{tabular}

يتضح من الجدول السـابق أن قيمة ألفا مرتفعة ودالة احصيائياً، مما يدل على تمتع المقياس بدرجة مناسبة من الثبات . ثالثاً: مقياس التوجه نحو المستقبل (إعداد أبوبكروعبد الرسول، 2020): صممت هذه الأداة بهدف قياس التوجه الإيجابي نحو المستقبل، وتكون

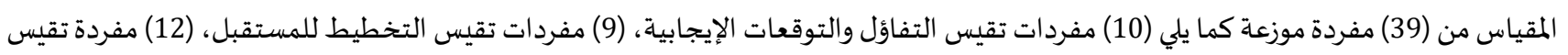

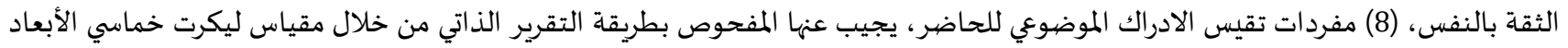

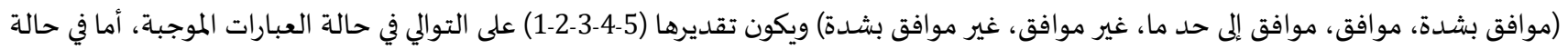

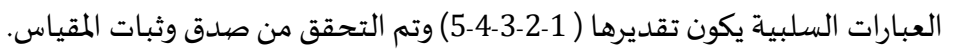

الخصيائص السيكومترية للمقياس:

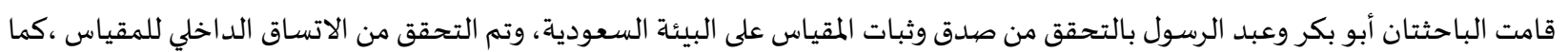

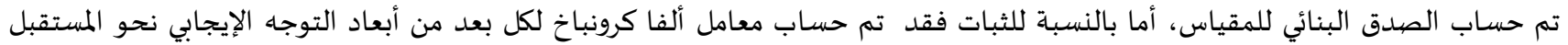

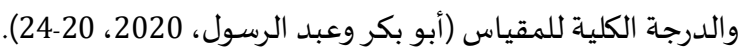

كما قامت الباحثة بالتحقق من صدق وثبات المقياس في الدراسة الحالية وفق الخطوات والتهاتية

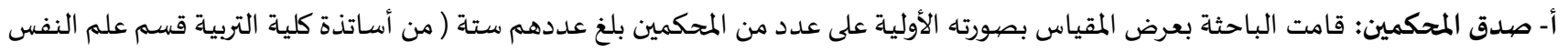
)، وذلك للاسترشاد بآرائهم حول مدى وضيوح العبارات وملائمتها لماوضعت لأجلاه ومدى مناسبة العبارات للمحور الذي تنتمي إليه، وتم إجراء التعديلات في ضوء آراء المحكمين. ب-الاتساق الداخلي لمقياس التوجه الإيجابي نحو المستقبل: تم التحقق من الاتساق الداخلي للمقياس حيث تم حساب معاملات الارتباط بين درجة

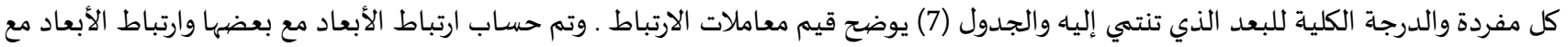

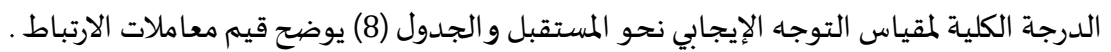

\begin{tabular}{|c|c|c|c|c|c|c|c|}
\hline الارتباط بالبعد & العبارة & الارتباط بالبعد & العبارة & الارتباط بالبعد & العبارة & الارتباط بالبعد & العبارة \\
\hline $.440^{* *}$ & 31 & $.668^{* *}$ & 21 & $.671^{* *}$ & 11 & $.790 * *$ & 1 \\
\hline $.317^{* *}$ & 32 & $.725^{* *}$ & 22 & $.570^{* *}$ & 12 & $.833^{* *}$ & 2 \\
\hline $.696^{* *}$ & 33 & $.618^{* *}$ & 23 & $.601^{* *}$ & 13 & $.827^{* *}$ & 3 \\
\hline $.727^{* *}$ & 34 & $.592^{* *}$ & 24 & $.605^{* *}$ & 14 & $.732^{* *}$ & 4 \\
\hline $.703^{* *}$ & 35 & $.511^{* *}$ & 25 & $.480^{* *}$ & 15 & $.813^{* *}$ & 5 \\
\hline $.751^{* *}$ & 36 & $.461^{* *}$ & 26 & $.622^{* *}$ & 16 & $.482^{* *}$ & 6 \\
\hline $.727^{* *}$ & 37 & $.490 * *$ & 27 & $.577^{* *}$ & 17 & $.554^{* *}$ & 7 \\
\hline $.758^{* *}$ & 38 & $.619^{* *}$ & 28 & $.455^{* *}$ & 18 & $.829^{* *}$ & 8 \\
\hline \multirow[t]{2}{*}{$.724^{* *}$} & 39 & $.575^{* *}$ & 29 & $.525^{* *}$ & 19 & $.672^{* *}$ & 9 \\
\hline & & $.571^{* *}$ & 30 & $.306^{* *}$ & 20 & $.801^{* *}$ & 10 \\
\hline
\end{tabular}

**. Correlation is significant at the 0.01 level (2-tailed)

ويتضح من الجدول (7) أن جميع قيم معاملات الارتباط بين العبارات والبعد الذي تنتمي إليه كانت قيماً موجبة ودالة إحصائياً، وتراوحت بين (455. -833.)عند مستوى دلالة 0.01 ، وتشير هذه النتيجة إلى أن عبارات المقياس تتمتع بدرجة مناسبة من الاتساق الداخلي .

\begin{tabular}{|c|c|c|c|c|}
\hline الدرجة الكلية & الادراك الموضيوعي & الثقة بالنفس & التخطيط & \\
\hline $.524^{* *}$ & $.524^{* *}$ & $.635^{* *}$ & $.557^{* *}$ & التفاؤل والتوقعات الإيجابية \\
\hline $.429^{* *}$ & $.429 * *$ & $.557^{* *}$ & & التخطيط \\
\hline $.706^{* *}$ & $.706^{* *}$ & & & الثقة بالنفس \\
\hline $1.000^{* *}$ & & & & الادراك الموضيوعي للحاضر \\
\hline
\end{tabular}

**. Correlation is significant at the 0.01 level (2-tailed).

يتضح من الجدول (8) أن جميع قيم معاملات الارتباط بين الأبعاد مع بعضها وترابط الأبعاد مع الدرجة الكلية للمقياس كانت قيماً موجبة ودالة إحصائياً عند مستوى دلالة 0.01 وتشير هذه النتيجة إلى أن جميع أبعاد المقياس تتمتع بدرجة مناسبة من الاتساق الداخلي. 
ثبات مقياس التوجه الإيجابي نحو المستقبل: للتأكد من ثبات أداة الدراسة تم حساب معامل ألفا كرو نباخ Alpha a'Cronbach للاستبانة بعد

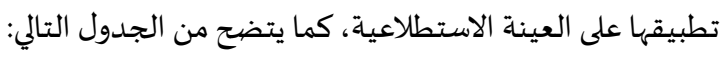

جدول (9): ثبات مقياس التوجه الإيجابي نحو المستقبل باستخدام معامل ألفا كرو نباخ المباخ

\begin{tabular}{|c|c|c|c|}
\hline الانحراف المعياري & المتوسط & معامل ثبات ألفا & مقياس التوجه الإيجابي نحو المستقبل \\
\hline 18.28924 & 150.6982 & .922 & \\
\hline
\end{tabular}

يتضح من الجدول السـابق أن قيمة ألفا مرتفعة ودالة احصائياً، مما يدل على تمتع المقياس بدرجة مناسبة من الثبات.

نتائج الدراسة وتفسيرها :

سعت الدراسة الحالية إلى الاجابة عن مجموعة من الأسئلة، وهي:

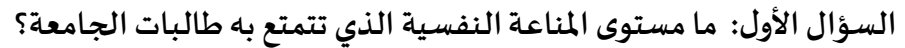

\begin{tabular}{|c|c|c|c|c|c|c|}
\hline الدلالة & قيمة ت & متوسط المجموعة & المتوسط النظري & الانحراف المعياري & ن & المتغير \\
\hline .000 & 28.644 & 158.3673 & 120 & 22.21263 & 275 & المناعة النفسية \\
\hline
\end{tabular}

تبين النتائج الموضحة في الجدول (10) أن قيمة المتوسط الحسابي الفعلي لدرجات أفراد العينة على مقياس المناعة النفسية 158.3673 بينما

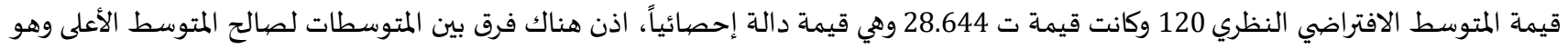

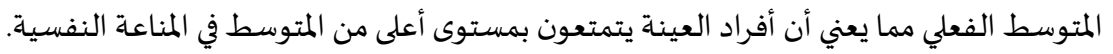
وتعزو الباحثة الارتفاع فوق المتوسط للمناعة النفسية إلى عدة عوامل منها أن عينة الدراسة من طالبات قسم علم النفس، فمن الممكن أن تكون

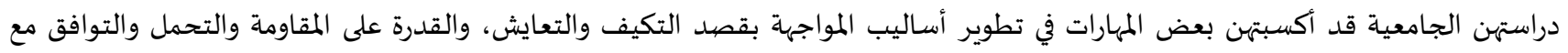
المواقف التي يتعرضون لها، كما أن حضور الطالبات للدورات والبرامج التدريبية التابعة لوحدة الارشاد والتوجياه في الكلية والتي تتضمن فنيات التهات وأنشطة

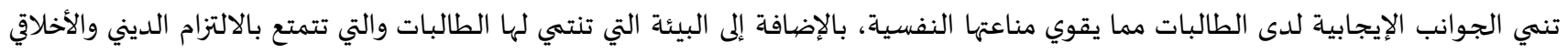

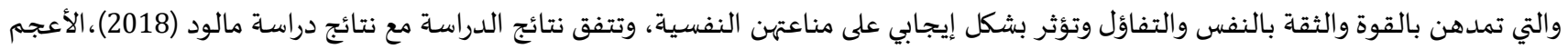

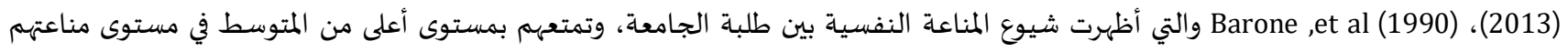

السؤال الثاني: ما مستوى المسـاندة الاجتماعية الذي تتمتع به طالبات الجامعة؟

\begin{tabular}{|c|c|c|c|c|c|c|}
\hline الدلالة & قيمة ت & متوسط المجموعة & المتوسط النظري & الانحراف المعياري & ن & المتغير \\
\hline .000 & -33.963 & 58.7855 & 75 & 7.91708 & 275 & المسساندة الاجتماعية \\
\hline
\end{tabular}

ويتبين من الجدول (11) أن قيمة المتوسط الحسابي الفعلي لدرجات أفراد العينة على مقياس المساندة الاجتماعية 75 وكاني

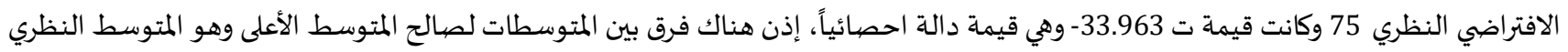

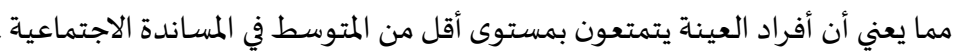

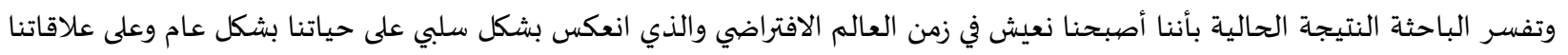

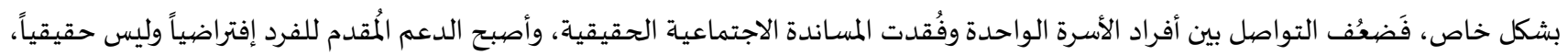

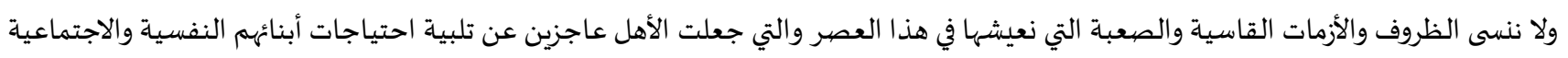
والاقتصادية، وترى الباحثة أنه من الممكن أن يكون المستوى الأقل من المتوسط للمساندة الاجتماعية يعود إلى مجموعة من العوامل النفسية

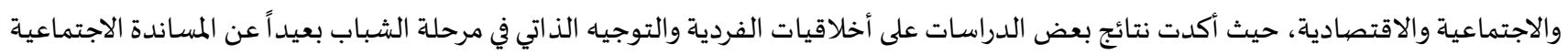

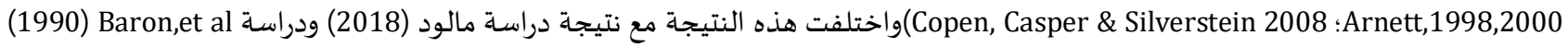

وأن طلبة الجامعة يتمتعون بمساندة اجتماعية .

السؤال الثالث: ما مستوى التوجهات المستقبلية الذي تتمتع به طالبات الجامعة؟ بـأه

\begin{tabular}{|c|c|c|c|c|c|c|}
\hline \multicolumn{7}{|c|}{ جدول (12): اختبارت لعينة واحدة للتعرف على مستوى التوجه الإيجابي نحو المستقبل } \\
\hline الدلالة & قيمة ت & متوسط المجموعة & المتوسط النظري & الانحراف المعياري & ن & المتغير \\
\hline .000 & -320.878 & 31.6618 & 117 & 4.41032 & 275 & الممساندة الاجتماعية \\
\hline
\end{tabular}


ويتبين من الجدول (12) أن قيمة المتوسط الحسابي الفعلي لدرجات أفراد العينة على مقياس التوجاه الإيجابي نحو المستقبل 320.878 المباد 31.6618 بينما

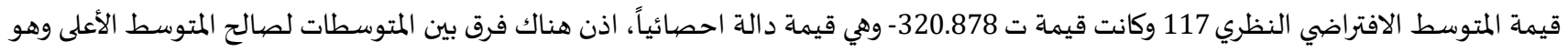
المتوسط النظري مما يعني أن أفراد العينة يتمتعون بمستوى أقل من المتوسط في التوجها الإيجابي نحو المستقبل. ويمكن تفسير هذه النتيجة بالرجوع إلى كل من السياقين البيئي والزمني اللذين ينتميان إليهما شباب الجامعة، وبالرجوع إلى السياق البيئي فهم

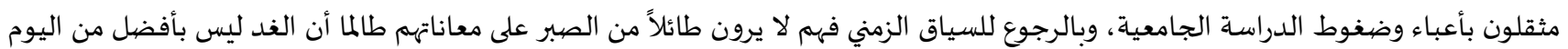

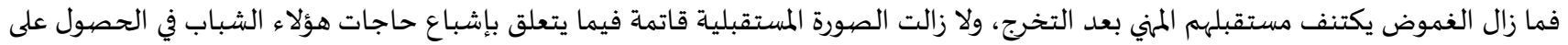

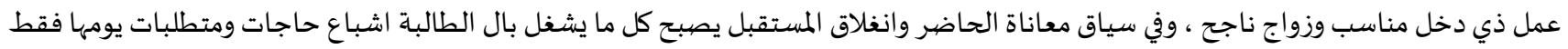

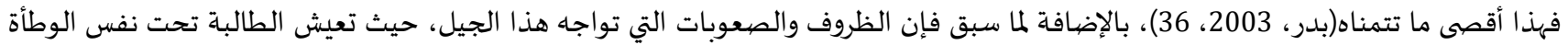

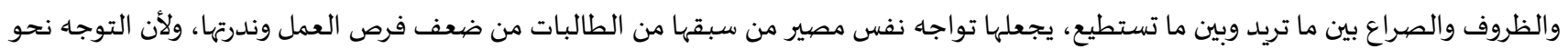
المستقبل يرتبط بما يمر باه الفرد من أحداث في الوقت الحاضر، فإما أن يكون الواقع منشطاً ومساعداً يجعله واثقاً ومتفائلاً، وإما أن يكون محبطاً

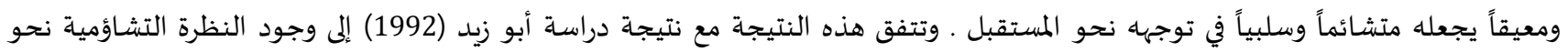

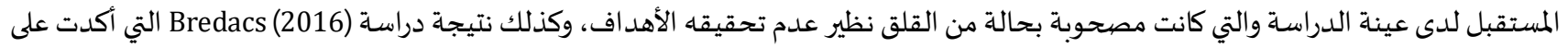

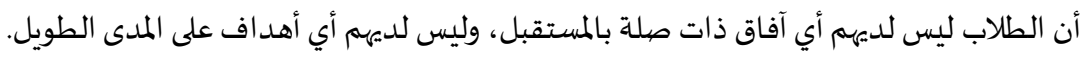

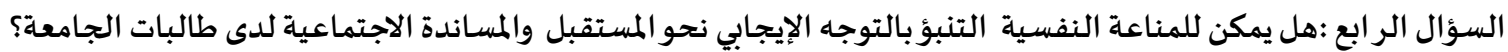

جدول (13): الاحصاءات الوصفية للمتغيرات التي ادخلت في معادلة الانحدار

\begin{tabular}{|c|c|c|c|}
\hline الانحراف المعياري & المتوسط & العدد العد & الأبعاد \\
\hline 4.41032 & 31.6618 & 275 & التوجه المستقبلي \\
\hline 7.91708 & 58.7855 & 275 & المسساندة الاجتماعية \\
\hline 22.21263 & 158.3673 & 275 & المناعة النفسية \\
\hline
\end{tabular}

وبالنظر إلى الجدول (13) نجد أن متوسط أداء طالبات عينة الدراسة على مقياس التوجه المستقبلي (31.6618) بانحراف معياري (4.41032) كما بلغ متوسط أداء طالبات عينة الدراسة على مقياس المساندة الاجتماعية (58.7855) بانحراف معياري (1585) (7.91708) و كما بلغ متوسط أداء طالبات عينة الدراسـة على مقياس المناعة النفسية (158.3673) بانحراف معياري (22.21263) . ثم تم فحص نموذجية الانحدار الكلي باستخدام تحليل التباين

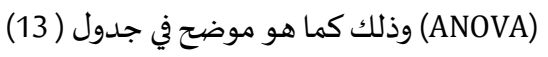

جدول (14): تحليل التباين ANOVAa

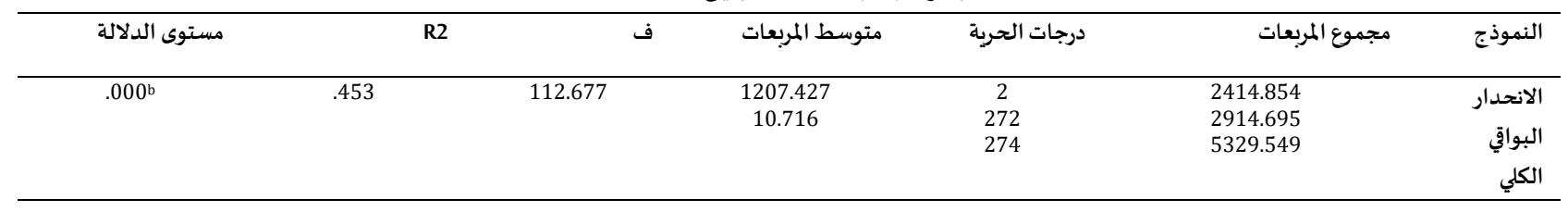

ويبين الجدول (14) أن النموذج العام لتحليل الانحدار يبين أن المتفيرات المستقلة ( المناعة النفسية والمساندة الاجتماعية) يعملان كمتنبئ ناجح بالمتغير التابع التوجاء نحو المستقبل من خلال جدول إندول تحليل التباين .

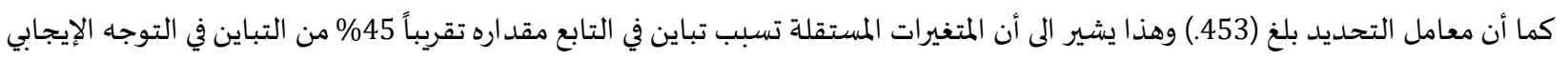

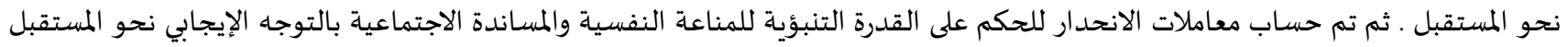

وذلك كما هو موضح بالجدول (15)

\begin{tabular}{|c|c|c|c|c|c|}
\hline \multirow{2}{*}{ مستوى الدلالة } & \multirow[t]{2}{*}{ قيمة ت } & معامل الانحدار & \multicolumn{2}{|c|}{ معامل الانحدار الخام } & \multirow[t]{2}{*}{ النموذج } \\
\hline & & Beta & B & الخطأ المعياري & \\
\hline $\begin{array}{l}.000 \\
.300\end{array}$ & $\begin{array}{l}5.847 \\
1.039\end{array}$ & & 9.672 & 1.654 & الثابت ل \\
\hline \multirow[t]{2}{*}{.000} & $\begin{array}{c}1.039 \\
12.068\end{array}$ & $\begin{array}{l}.055 \\
.642\end{array}$ & $\begin{array}{l}.031 \\
.127\end{array}$ & $\begin{array}{l}.030 \\
.011\end{array}$ & الممساندة الاجتماعية \\
\hline & & & & & المناعة النفسية \\
\hline
\end{tabular}

يبين الجدول (15) أن قيمة معامل الانحدار للمساندة الاجتماعية (031.) وكما بلغت قيمة معامل الانحدار المعياري (055.) وقد كانت غير دالة، مما يشير إلى أن المساندة الاجتماعية لم تتنبأ بالتوجه الإيجابي نحو المستقبل، بينما كانت قيمة معامل الانحد اردار للمناعة النفسية (127.) وقيمة معامل 
الانحدار المعياري (642.) وقد كانت دالة عند مستوى (0.01) مما يشير إلى نجاح متغير المناعة النفسية في التنبؤ بالتوجه الإيجابي نحو المستقبل، يمكن أن نلخص معادلة الانحدار الخام كالتالي :

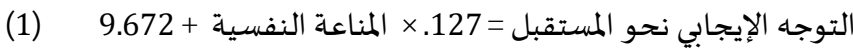

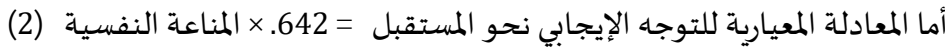

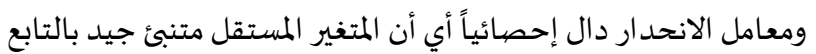
وتفسر الباحثة النتيجة بأن المناعة النفسية تعمل كبناء واقي من الاحباطات، وتجعل الطالبة أكثر قدرة على التوافق مع متطلبات المحيط المبات الذي

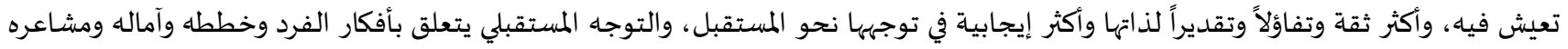

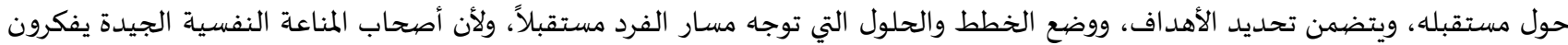

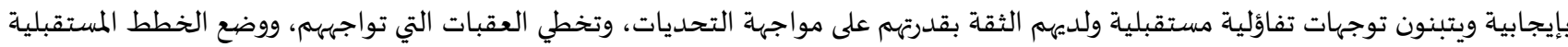
والقدرة على تنفيذها (حسنين،2013، 28) .كما يرى (جولدسين، بروكس، 2011 ،515- 514) أن من بين الخصائص التي تميز التوجه العقلي

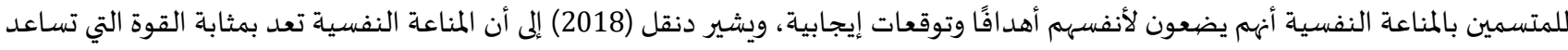
الانسان في التغلب على الصعوبات ومواجهة التحديات وتجاوز العثرات لتحقيق النجاحات والتوجهات الإيجابية نحو المستقبل، وكما تؤكد عصفور

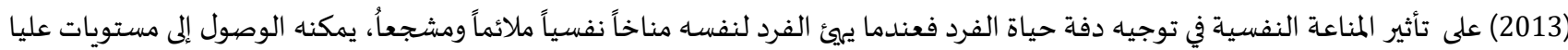

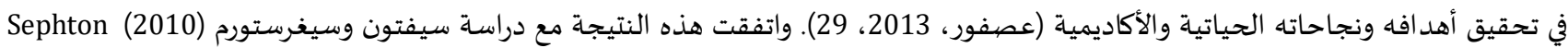
Admire (2011) من حيث وجود علاقة إيجابية بين التوقعات المتفائلة و المناعة، وأن الطلاب المتفائلين ذوي التوجهات

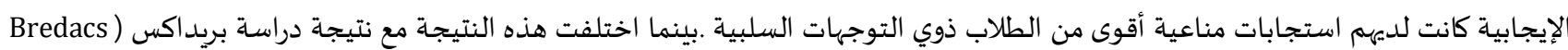

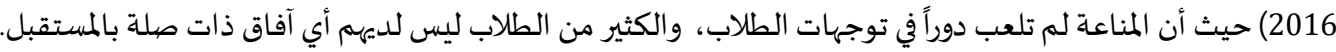

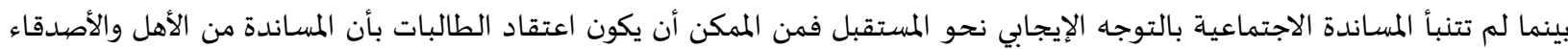
والجيران في الوقت الراهن ليس لها علاقة بالمستقبل وإنما من الممكن أن تكون المساندة مفيدة في الوقت الحاضر للتغلب على العقبات والتفوق والنجاح

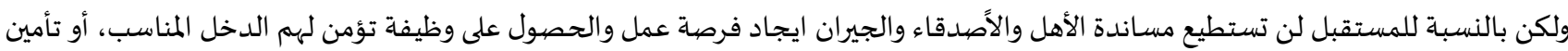
حياة مهنية ناجحاة، فالأمر يعتمد على سياسات التشغيل والتوظيف ولا علاقة له بالمساندة الاجتماعية، فالتوجه المستقبلي يرتبط برغبة الفرد في

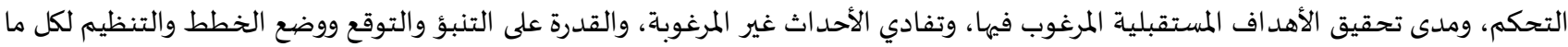
هو قادم (صادق، 2019، 420) وقد أوضح (يونس، 2011) أن قدرة المراهق تزداد في اتخاذ القرارات، والتفكير لنفسـه بنفسـا،، ويتضمن ذلك الكهيه الاختيار والحكم والثقة بالنفس واستقلالية التفكير، والتفريق بين الواقعي والمثالي، وتوجياء الاهتمام إلى العمل والمهنة، واختيار مهنة ما، والاستعد اد لممارستها

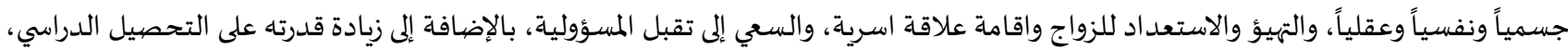

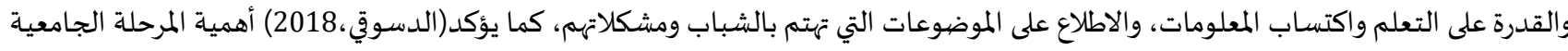

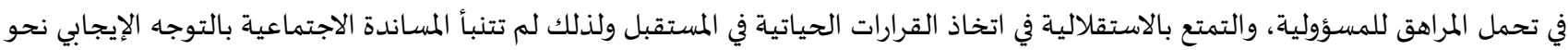
Anubhuti (2018) Seginer (2003) ودراسـة المستقبل في الدراسة الحالية .واختلفت هذه النتيجة مع نتائج الدراسات السابقة مثل دراسة سيجنة

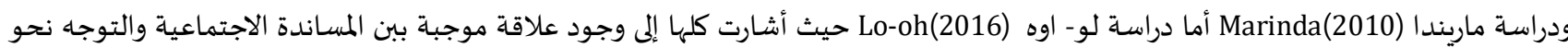

المستقبل .

السؤال الخامس: هل توجد فروق بين مرتفعي المناعة النفسية ومنخفضي المناعة النفسية على مقياس التوجه الإيجابي نحو المستقبل؟ للإجابة على السؤال الخامس تم بداية حساب الدرجة الكلية للمناعة النفسية ثم حساب الإبراعين الأعلى والأدنى لاستخراج المجموعتين العليا والدنيا على متغير التوجاء الإيجابي نحو المستقبل

جدول(16): الفروق بين منخفضي المناعة النفسية ومرتفعي المناعة النفسية على مقياس التوجه الإيجابي نحو المستقبل (الدرجة الكلية)

\begin{tabular}{|c|c|c|c|c|c|c|}
\hline الدلالة & قيمة ت & الانحراف المعياري & المتوسط & العدد & المناعة النفسية & \\
\hline .000 & 12.034 & $\begin{array}{l}3.09507 \\
3.96634\end{array}$ & $\begin{array}{l}35.3333 \\
27.9420\end{array}$ & $\begin{array}{l}66 \\
69\end{array}$ & الأعلى & للمستقبل \\
\hline
\end{tabular}

يبين الجدول (16) أن متوسط الفئة العليا (35.3333) بانحراف معياري (3.09507) وبلغ متوسط الفئة الدنيا (27.9420) وبانحراف معياري (3.96634)، وتم حساب الفروق بينهم باستخدام اختبار(ت) لمجموعتين مستقلتين لحسـاب دلالة الفروق بين أداء الفئتين العليا والدنيا، كما يبين 
الجدول (15) أن قيمة (ت) للفروق بلغت (12.034) وقد كانت دالة احصائياً مما يشير إلى وجود فروق دالة احصائياً بين منخفضي المناعة النفسية ومرتفعي المناعة النفسية على مقياس التوجه المستقبلي (كدرجة كلية) .

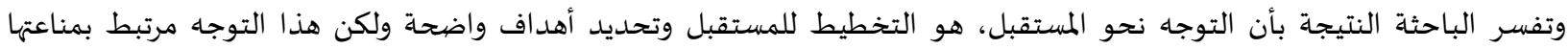
النفسية، وبما تحمله من نظرة تفاؤلية وثقة في النفس، وهذا ما أكده مرسي (2000) بأن المناعة النفسية هي قدرة الفرد على مواجهة الأزمات، وتحمل

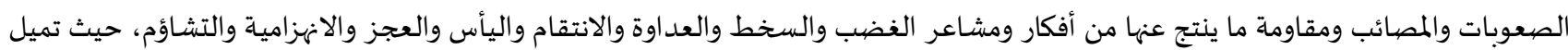

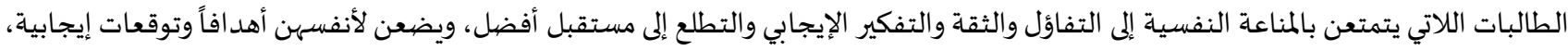

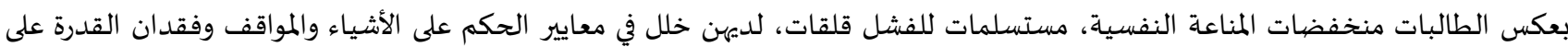
التحكم الذاتي، ويركزن على الوقت الحاضر أكثر من تفكيرهن في مستقبلهن، واتفقت هذه النتيجة مع نتائج دراسة آدماير Admire (2011) حيث بينت

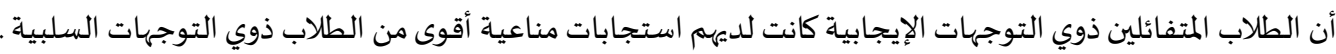

السؤال السـادس: هل توجد فروق بين مرتفعي ومنخفضي المسـاندة الاجتماعية على مقياس التوجه نحو المستقبل؟

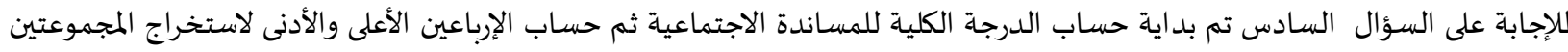

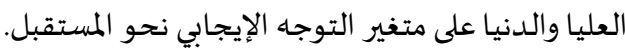

جدول (17): الفروق بين منخفضي المساندة الاجتماعية ومرتفعي المساندة الاجتماعية على مقياس التوجه الإيجابي نحو المستقبل (الدرجة الكلية) باستخدام

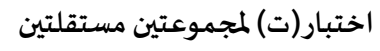

\begin{tabular}{|c|c|c|c|c|c|c|}
\hline الدلالة & ق قيمة ت & الانحراف المعياري & المتوسط & العدد & الاجتماعية & \\
\hline .000 & 6.803 & $\begin{array}{l}3.70529 \\
4.72768\end{array}$ & $\begin{array}{l}34.2188 \\
29.2432\end{array}$ & $\begin{array}{l}64 \\
74\end{array}$ & الأأعلى & للمستقبل \\
\hline
\end{tabular}

يبين الجدول (17) أن متوسط الفئة العليا (34.2188) بانحراف معياري (3.70529) وبلغ متوسط الفئة الدنيا (29.2432) وبانحراف معياري (4.72768) ، وتم حساب الفروق باستخدام اختبار (ت) لمجموعتين مستقلتين لحساب دلالة الفروق بين أداء الفئتين العليا والدنيا، كما يبين الجدول

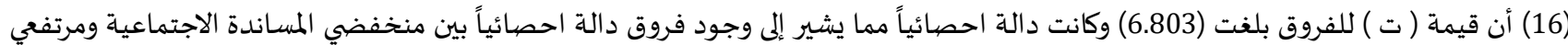
المسـاندة الاجتماعية على مقياس التوجه المستقبلي ( كدرجة كلية). وتشير النتيجة إلى أن مرتفعي المساندة الاجتماعية أكثر توجهاً نحو المستقبل من منخفضي المئي المساندة الاجتماعية، ويمكن تفسير ذلك بأن من المتوقع

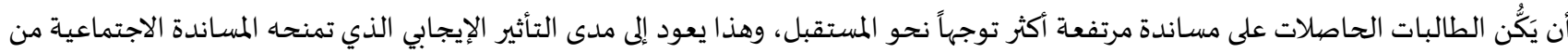

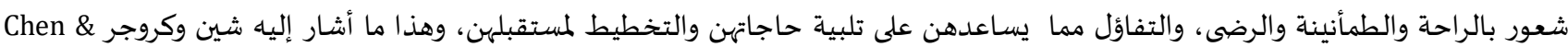
Kruger (2017) حيث أن توجهات الفرد نحو المستقبل تحددها فئتان من العوامل هما: عوامل داخلية ذاتية متصلة بالفرد مثل مستوى الطموح وصورة الفرد عن ذاته، وعوامل خارجية متصلة بالسياق الاجتماعي المحيط والذي يتضمن البيئة الأسرية والتعليمية والاجتماعية)( أبوبكر وعبد الماتد الرسول، 2020، 30) .كما أوضح (2016) في دراستـا أن هناك موردين اثنين من الموارد الشخصية والبيئية يسهمان في زيادة التوجهات الإيجابية نحو المستقبل هما التفاؤل والمساندة الاجتماعية. وتشير نتائج دراسة (2016) SO إلى ارتباط التوجها

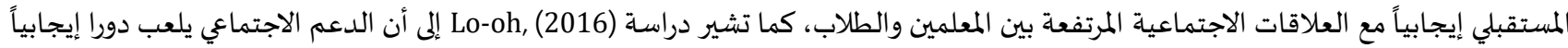

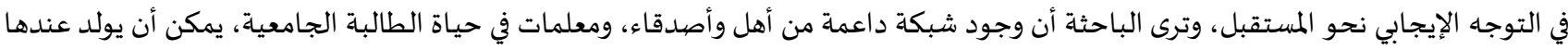

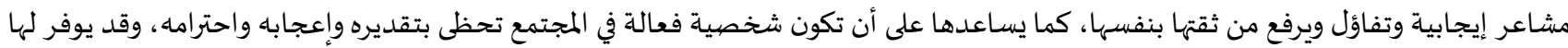

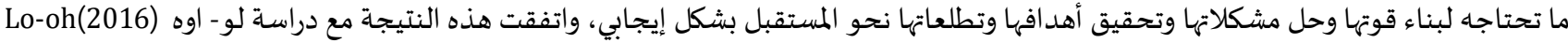

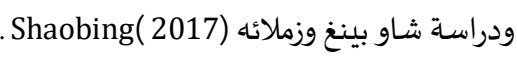
توصيات الدراسـة:

الاهتمام بالمناعة النفسية للطالبة الجامعية من خلال إعداد برامج ارشادية لتنمية المناعة النفسية. إعداد برامج تدريبية لتنمية التوجه الإيجابي نحو المستقبل في المرحلة الجامعية لتدعيم قدرة الطالبات على التعامل بإيجابية مع المشكلات التي يتعرضن لها. توفير البرامج الإرشادية للأسرة وتفعيل دور الارشاد الأكاديمي للطالبات لتوفير المساندة الاجتماعية التي تساعدهن على مواجهة التحديات في حياتهم الحاضرة والمستقبلية. 


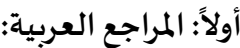

1. الأحمد، محمد رفيق (2020). المناعة النفسية وعلاقتها بالسعادة لدى عينة من الطلاب الأيتام بالمرحلة الأساسية العليا في محافظة جرش. مجلة

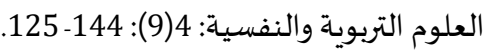

2. الأعجم، ناديا رزوقي (2013). المناعة النفسية وعلاقتها بالمساندة الاجتماعية لدى طلبة الجامعة. رسالة ماجستير. كلية التربية للعلوم الانسانية.

جامعة ديالى.

3. بدر، ابراهيم محمود (2003). مستوى التوجه نحو المستقبل وعلاقته ببعض الاضطرابات لدى الشباب الجامعي دراسة مقارنة بين عينات

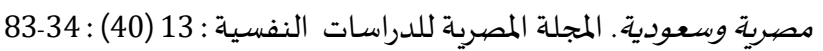
4. أبو بكر ، نشوة وعبد الرسول، حنان (2020). فاعلية برنامج إشادي لتنمية التوجه الإيجابي نحو المستقبل كمدخل لتحسين المرونة الأكاديمية

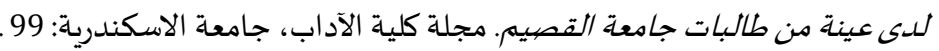
5. الجزار، رانيا (2018). المناعة النفسية لدى طلاب الجامعة وعلاقتها بالذكاء الأخلاقي والأداء الأكاديهي. مجلة البحث العلمي في الآداب:19(7) : 1-

6. جولدسين، سام، و بروكس ،روبرت ب. (2011). الصهود لدى الأطفال. ت: صفاء الأعسر، القاهرة: المركز القومي للترجمة. 7. طنطا. مجلة كلية الآداب: 21 (3): 992-1083. 8. حسان، ولاء اسحق (2009). فاعلية برنامج /شادي مقترح لزيادة مرونة الأنا لدى طالبات الجامعة الاسلامية بغزة. رسالة ماجستير غير منشورة.

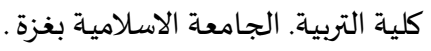
9.9

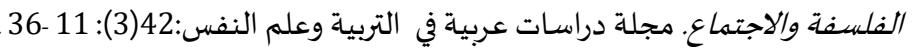
10. حكيمة، آيت؛ أحمد، فاضلي ورشيد، مسيلي (2011). أهمية المساندة الاجتماعية في تحقيق التوافق النفسي والاجتماعي لدى الشباب البطال. مجلة العلوم الاجتماعية والانسانية: 2: 1-38.

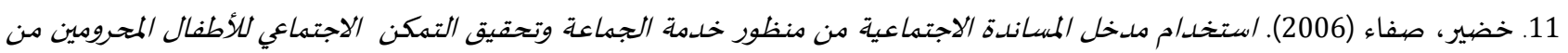
الرعاية الأسرية. مجلة كلية التربية. جامعة حلوان.

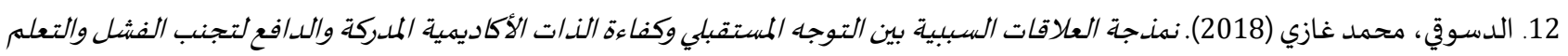

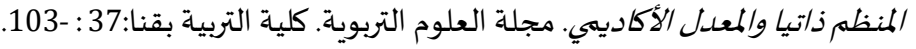

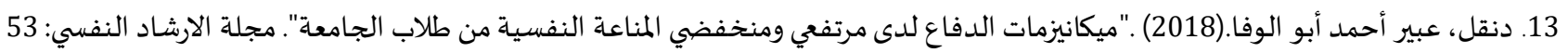

14. أبو زيد، نبيلة (1992). النظرة المستقبلية لدى شباب الجامعة من الجنسين. القاهرة، الهيئة المصرية العامة للكتاب.

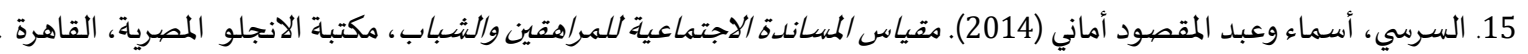
16. الشناوي، محمد محروس ، و عبد الرحمن، محمد السيد (1994) المساندة الاجتماعية والصحة النفسية مراجعة نظرية ودراسات تطبيقية. مكتبة الانجلو المصرية. القاهرة. 17. صادق، مروة أحمد (2019) . الإسهام النسبي لمعتقدات فاعلية الذات الأكاديمية والتوجه المستقبل" المهني الأسري" في التنبؤ بالتوافق مع الحياة

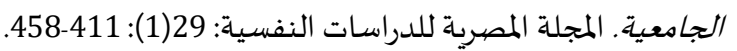

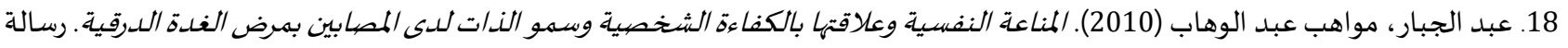
دكتوراه، الجامعة المستنصرية.

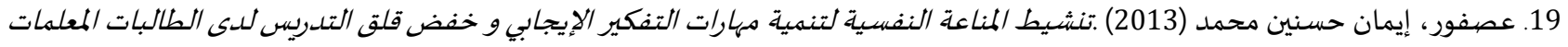

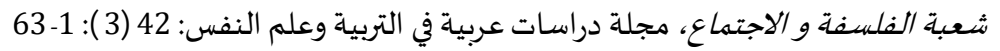

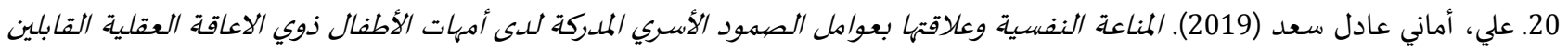

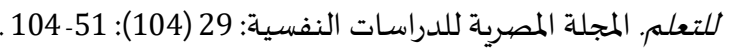
21. عوض، رئيفة (2001) ضغنوط المراهقين وههارات المواجهة التشخيص والعلاج .القاهرة. مكتبة الهضضة المصرية.

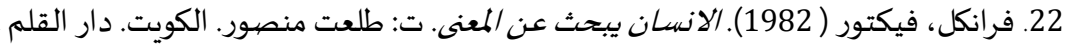




$$
\begin{aligned}
& \text { 23. مالود، فاطمة ذياب (2018). المناعة النفسية وعلاقتها بالمساندة الاجتماعية لدى طلبة كلية التوبية للعلوم الانسانية. جامعة كربلاء. مجلة } \\
& \text { الباحث: 11(20): 416-430. } \\
& \text { 24. محمد علي، قيس (2010). علاقة عمل طلاب المرحلة الاعد/دية بعد الدوام باتجاهاتهم المستقبلية. جامعة الموصل. مجلة أبحاث كلية التربية } \\
& \text { الأسساسية: 10( 3): 51-23. } \\
& \text { 25. مرسي، كمال ابراهيم.( 2000). السعادة وتنمية الصحة النفسية. القاهرة، دار النشر للجامعات. } \\
& \text { 26. مطلك، فاطمة.(2007). قياس الاتجاهات المستقبلية. مجلة كلية الآداب: 78: 348-378 }
\end{aligned}
$$

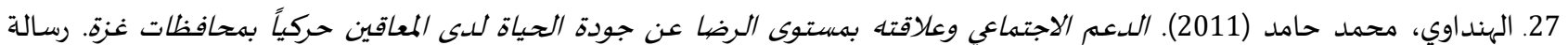

$$
\begin{aligned}
& \text { ماجستير. جامعة الأزهر . مان. } \\
& \text { 28. يونس، ربيع شعبان( 2018). علم نفس النمو الطفولة والمراهقة. ط2، الدمام، مكتبة المتنبي. }
\end{aligned}
$$

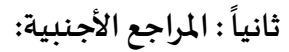

1. Admire. (2011). How a positive your Immune System, www.Psycholog.about.com

2. Albert, L, E., Albert- Lorincz, M., Kadar, A., Krizbari, T. \& Marton R. (2012). Relationship between the characteristics of the psychological immune system and the emotional tone of personality in Adolescents. The new education reviews. 23: 1151103.

3. Anubhuti, Dubey. (2018). Satisfied with Retired Life: Role of Psychological Immunity and Social Networks. Journal of the Indian Academy of Geriatrics. 14: 192-192.

4. Arnett, J.J. (1998). Learning to stand alone: the contemporary American transition to adulthood in cultural and historical context. Human Development, (41): 295-315, https://doi.org/10.1159/000022591.

5. Arnett, J.J. (2000). Emerging adulthood: A theory of development from the late teens through the twenties. American Psychologist, 55: 469- 480.

6. Bar, M. (2010). Wait for the Second Marshmallow? Future -Oriented Thing and Delayed Reward Discounting in the Brain. Neuron, 66(1): 4-5, https://doi.org/10.1016/j.neuron.2010.04.001.

7. Baron, R. S., Cutrona, C. E., Hicklin, D., Russell, D. W., \& Lubaroff, D. M. (1990). Social support and immune function among spouses of cancer patients. Journal of personality and social psychology, 59(2):344-35, https://doi.org/10.1037/00223514.59.2.344

8. Bhardwaj, A. \& Agrawal, G. (2015). Concept and applications of psych immunity (defense against mental illness): importance in mental health scenario. Journal of Multidisciplinary Research. 1(3): 6-15.

9. Bredacs, Alice Mária(2016). Psychological Immunity Research to improvement of the Professional Teacher Training's National Methodological and Training Development. Practice and Theory in Systems of Education, 11 (2): 118- 141, https://doi.org/10.1515/ptse-2016-0014.

10. Caplan, g. (1974). support systems community and community mental health. New. york, behavioral publishers

11. Copen, C., Casper, L.M., \& Silverstein, M. (2008). Changes in values towards individualism and collectivism among young adults". Draft paper

12. Fuligni, A.J. \& Pedersen, S. (2002). Family obligation and the transition to young adulthood. Developmental Psychology, 38(5): 856-868, https://doi.org/10.1037/0012-1649.38.5.856.

13. Gilbert, T., Pinel, C., Wilson, D., Blumberg, J., \& Wheatley, P. (1998). Immune neglect: A source of durability bias in affective forecasting. Journal of Personality and Social Psychology, 75(3): 617-638, https://doi.org/10.1037/0022-3514.75.3.617.

14. Holman, E., \& Silver, R. (2005). Future -oriented Thinking and Adjustme nt in a Nationwide Longitudinal. Study Following the September11 th Terrorist Attacks Motivation and Emotion .29(4).

15. House, J. S. (1981). work stress and social support. reading, mass, Addison-Wesley. 54:158.

16. Kobassa, S.C. (1979). Stressful life events, Personality, and health: an inquiry into hardiness, Journal of personality and social psychology, 42(1):168-177.

17. Lo-oh, Joseph Lah. (2016). The role of social support in the future orientation of emerging adults in Cameroon. European Journal Social Sciences, University of Buea, Cameroon, 4 (7): 43-54.

18. Marinda, Harrell-Levy. (2010). Contributions of Social Support, Future Orientation and a School Transition to School Engagement Among High School Adolescents, Human Development and Family Studies. Master Thesis.

19. Manago, A.M., Taylor, T. \& Greenfield, P.M. (2012). Me and my 400 friends: The anatomy of college students Facebook Networks, their communication patterns, and well-being. Developmental Psychology. Advance online publication. doi:10.1037/a0026338. 
20. Olah, A. (2002). Positive traits: Flow and psychological immunity. Paper presented at the First International Positive Psychology Summit. 3-6 October, Washington, D.C.

21. Seginer, R. (2009). Future orientation: developmental and ecological perspectives. New York: Springer Series of human exceptionality

22. Seginer, R. (2003). Adolescent Future Orientation an Integrated Cultural and Ecological, Perspective. Online Readings in psychology and Culture, 6(1).

23. Sephton, Sandra E., Segerstrom, Suzanne C. (2010). Optimistic Expectancies and Cell-Mediated Immunity, The Role of Positive Affect, Aps Association psychological science .21, 3.

24. Shaobing Su, Xiaoming Li, Danhua Lin, \& Maoling Zhu. (2017). Future Orientation, Social Support, and Psychological Adjustment among Left-behind Children in Rural China: A Longitudinal.

25. Snyder, C.R. Shorey, H.S., Cheavens, J., Pulvers, K.M, Adams, V.H. \& Wiklund, C. (2002). Hope and academic success in college, Journal of Educational Psychology, 94(4): 820-826, https://doi.org/10.1037/0022-0663.94.4.820.

26. SO, S., Voision, D. R., Burnside, A. \& Gaylord -Harden, N.K. (2016). Future orientation and health related factors among African American Adolescents. Children \& Youth Services Review, 61: 15-21, https://doi.org/10.1016/j.childyouth.2015.11.026.

27. Steinberg, I., Graham, S., Obrien, I., Woolard, J., Cauffman, E., \& Banich, M. (2009). Age Differences in Future Orientation and Delay Discounting. Child Development, 80(1): 28-44, https://doi.org/10.1111/j.1467-8624.2008.01244.x.

28. Yafit, Sulimani-Aidan. (2016). Future Expectations as a Source of Resilience among Young People Leaving Care. British Journal of Social Work. 46(4). DOI: https://doi.org/10.1093/bjsw/bcw077

29. Zhang, J., Zhao, G., Li, X., Hong, Y., Fang, X., Barnett, D., Lin, X., Zhao, J. \& Zhang, L., (2009). Positive Future Orientation as a mediator between traumatic events and mental health among children affected by HIV/ AIDS in rural china. AIDS Scare, 21(12): 1508-1516, https://doi.org/10.1080/09540120902923048. 


$$
\text { المجلة الدولية للدراسـات التربوية والنفسية }
$$

International Journal of Educational \& Psychological Studies (EPS)

\title{
Psychological immunity and social support as predictors of positive orientation towards the future for a sample of students of Qassim university
}

\section{Hanan Khalil al-Halabi}

Assistant Professor of Mental Health, Department of Psychology, College of Education Buraida

Qassim University, KSA

dr.hanan9591@yahoo.com

\author{
Received : 15/8/2020 Revised : 22/8/2020 Accepted : 30/8/2020 DOI : https://doi.org/10.31559/EPS2021.9.2.8
}

Abstract: The study aimed to identify the role of psychological immunity and social support in predicting the positive orientation towards the future for university students, and identifying the level of psychological immunity, social support and positive orientation towards the future for university students, In addition to Identify the differences between those with low psychological immunity and high , and the differences between those with low social support and high, on the scale of positive orientation towards the future, the study sample consisted of (275) female students from the College of Education. The study was based on the comparative predictive descriptive approach, and used the psychological immunity scale, social support scale for adolescents and young people, and orientation towards the future. The study found the following results: the sample individuals have a higher-than-average level in psychological immunity, and a lower-than-average level in social support and orientation towards the future, and psychological immunity has a predictive capacity for a positive orientation towards the future, while social support does not predict a positive orientation towards the future. as the results indicated significant differences between those with low psychological immunity and high, and significant differences between those with low social support and high on the scale of positive orientation towards the future.

Kevwords: mental immunitv: social sunnort: nositive orientation towards the future.

\section{References:}

1. 'bd Aljbar, Mwahb 'bd Alwhab (2010). Almna'h Alnfsyh W'laqtha Balkfa'h Alshkhsyh Wsmw Aldat Lda Almsabyn Bmrd Alghdh Aldrqyh. Rsalt Dktwrah, Aljam'h Almstnsryh.

2. 'ly, Amany 'adl S'd (2019). Almna'h Alnfsyh W'laqtha B'waml Alsmwd Alasry Almdrkh Lda Amhat Alatfal Dwy Ala'aqh Al'qlyh Alqablyn Llt'lm. Almjlh Almsryh Lldrasat Alnfsyh: 29 (104): 51- 104.

3. 'sfwr, Eyman Hsnyn Mhmd (2013). Tnshyt Almna'h Alnfsyh Ltnmyh Mharat Altfkyr Aleyjaby W Khfd Qlq Altdrys Lda Altalbat Alm'lmat Sh'bt Alflsfh W Alajtma', Mjlt Drasat 'rbyh Fy Altrbyh W'Im Alnfs: 42 (3): 1- 63

4. ' wd, R'yfh (2001). Dghwt Almrahqyn Wmharat Almwajhh Altshkhys Wal'laj. Alqahrh. Mktbt Alnhdh Almsryh.

5. Ala'jm, Nadya Rzwqy (2013). Almna'h Alnfsyh W'laqtha Balmsandh Alajtma'yh Lda Tlbt Aljam'h. Rsalt Majstyr. Klyt Altrbyh Ll'lwm Alansanyh. Jam't Dyala .

6. Alahmd, Mhmd Rfyq (2020). Almna'h Alnfsyh W'laqtha Bals'adh Lda Eynh Mn Altlab Alaytam Balmrhlh Alasasyh Al'lya Fy Mhafzt Jrsh. Mjlt Al'lwm Altrbwyh Walnfsyh: 4(9): 144- 125.

7. Bdr, Abrahym Mhmwd (2003). Mstwa Altwjh Nhw Almstqbl W'laqth Bb'ed Aladtrabat Lda Alshbab Aljam'y Drash Mqarnh Byn 'ynat Msryh Ws'wdyh. Almjlh Almsryh Lldrasat Alnfsyh : 13 (40) : 34-83.

8. Abw Bkr, Nshwh W'bd Alrswl, Hnan (2020). Fa'lyt Brnamj Ershady Ltnmyh Altwjh Aleyjaby Nhw Almstqbl Kmdkhl Lthsyn Almrwnh Alakadymyh Lda 'ynh Mn Talbat Jam't Alqsym. Mjlt Klyt Aladab, Jam'eh Alaskndryh: 99.

9. Dnql, 'byr Ahmd Abw Alwfa. (2018)."Mykanyzmat Aldfa' Lda Mrtf'y Wmnkhfdy Almna'h Alnfsyh Mn Tlab Aljam'h". Mjlt Alarshad Alnfsy: $53:(2)$. 
10. Aldswqy, Mhmd Ghazy (2018). Nmdjh Al'laqat Alsbbyh Byn Altwjh Almstqbly Wkfa'h Aldat Alakadymyh Almdrkh Waldaf' Ltjnb Alfshl Walt'elm Almnzm Datya Walm'dl Alakadymy. Mjlt Al'lwm Altrbwyh. Klyt Altrbyh Bqna:37: -103.

11. Frankl, Fyktwr (1982). Alansan Ybhth 'n Alm'na. T: Tl't Mnswr. Alkwyt. Dar Alqlm.

12. Hjazy, Jwltan Hsn (2008). Alaghtrab Alnfsy W'laqth Baldaf'yh Llenjaz Waltwjh Almstqbly Lda Alshbab Aljam'y Alflstyny. Jam't Tnta. Mjlh Klyh Aladab: 21 (3): 992-1083.

13. Hkymh, Ayt; Ahmd, Fadly Wrshyd, Msyly (2011). Ahmyh Almsandh Alajtma'yh Fy Thqyq Altwafq Alnfsy Walajtma'y Lda Alshbab Albtal. Mjlt Al'elwm Alajtma'yh Walansanyh: 2: 1-38.

14. Alhndawy, Mhmd Hamd (2011). Ald'm Alajtma'y W'elaqth Bmstwa Alrda 'n Jwdh Alhyah Lda Alm'aqyn Hrkyaan Bmhafzat Ghzh. Rsalt Majstyr. Jam't Alazhr.

15. Hsan, Wla' Ashq (2009). Fa'lyt Brnamj Arshady Mqtrh Lzyadh Mrwnh Alana Lda Talbat Aljam'h Alaslamyh Bghzh. Rsalt Majstyr Ghyr Mnshwrh. Klyt Altrbyh. Aljam'h Alaslamyh Bghzh.

16. Hsnyn, Eyman Mhmd (2013). Tnshyt Almna'h Alnfsyh Ltnmyh Mha Rat Altfkyr Aleyjaby Wkhfd Qlq Altdrys Lda Altalbat Alm'lmat Sh'bh Alflsfh Walajtma'. Mjlh Drasat 'rbyh Fy Altrbyh W'lm Alnfs:42(3): 11 -36.

17. Aljzar, Ranya (2018). Almna'h Alnfsyh Lda Tlab Aljam'h W'laqtha Baldka' Alakhlaqy Walada' Alakadymy. Mjlt Albhth Al'lmy Fy Aladab: 19(7): 1-42.

18. Jwldsyn, Sam, W Brwks ,Rwbrt B. (2011). Alsmwd Lda Alatfal. T: Sfa' Ala'sr, Alqahrh: Almrkz Alqwmy Lltrjmh.

19. Khdyr, Sfa' (2006). Astkhdam Mdkhl Almsandh Alajtma'yh Mn Mnzwr Khdmh Aljma'h Wthqyq Altmkn Alajtma'y Llatfal Almhrwmyn Mn Alr'ayh Alasryh. Mjlt Klyt Altrbyh. Jam't Hlwan.

20. Malwd, Fatmh Dyab (2018). Almna'h Alnfsyh W'laqtha Balmsandh Alajtma'yh Lda Tlbt Klyt Altrbyh Ll'lwm Alansanyh. Jam't Krbla'. Mjlt Albahth: 11(20): 416-430.

21. Mhmd 'ly, Qys (2010). 'laqt 'ml Tlab Almrhlh Ala'dadyh B'd Aldwam Batjahathm Almstqblyh. Jam't Almwsl. Mjlt Abhath Klyt Altrbyh Alasasyh: 10(3): 23-51.

22. Mrsy, Kmal Abrahym. (2000). Als'adh Wtnmyh Alshh Alnfsyh. Alqahrh, Dar Alnshr Lljam'at.

23. Mtlk, Fatmh. (2007). Qyas Alatjahat Almstqblyh. Mjlt Klyh Aladab: 78: 348-378.

24. Sadq, Mrwh Ahmd (2019). Alesham Alnsby Lm'tqdat Fa'lyt Aldat Alakadymyh Waltwjh Almstqbl "Almhny Alasry" Fy Altnb' Baltwafq M' Alhyah Aljam'yh. Almjlh Almsryh Lldrasat Alnfsyh: 29(1): 411-458.

25. Alshnawy, Mhmd Mhrws, W 'bd Alrhmn, Mhmd Alsyd (1994) Almsandh Alajtma'yh Walshh Alnfsyh Mraj'h Nzryh Wdrasat Ttbyqyh. Mktbt Alanjlw Almsryh. Alqahrh.

26. Alsrsy, Asma' W'bd Almqswd Amany (2014). Mqyas Almsandh Alajtma'yh Llmrahqyn Walshbab, Mktbh Alanjlw Almsryh, Alqahrh .

27. Ywns, Rby' Sh'ban (2018). 'Im Nfs Alnmw Altfwlh Walmrahqh. T2, Aldmam, Mktbt Almtnby.

28. Abw Zyd, Nbylh (1992). Alnzrh Almstqblyh Lda Shbab Aljam'h Mn Aljnsyn. Alqahrh, Alhy'h Almsryh Al'amh Llktab. 